\title{
Review Article \\ Role of HOX Genes in Stem Cell Differentiation and Cancer
}

\author{
Seema Bhatlekar $\mathbb{D}^{1,2}$ Jeremy Z. Fields, ${ }^{3}$ and Bruce M. Boman $\mathbb{D}^{1,2,3,4}$ \\ ${ }^{1}$ Center for Translational Cancer Research, Helen F. Graham Cancer Center and Research Institute, Newark, DE, USA \\ ${ }^{2}$ Department of Biological Sciences, University of Delaware, Newark, DE, USA \\ ${ }^{3}$ CATX Inc., Princeton, NJ, USA \\ ${ }^{4}$ Kimmel Cancer Center, Thomas Jefferson University, Philadelphia, PA, USA
}

Correspondence should be addressed to Bruce M. Boman; brucemboman@gmail.com

Received 1 March 2018; Revised 8 May 2018; Accepted 15 May 2018; Published 22 July 2018

Academic Editor: Jing Huang

Copyright (c) 2018 Seema Bhatlekar et al. This is an open access article distributed under the Creative Commons Attribution License, which permits unrestricted use, distribution, and reproduction in any medium, provided the original work is properly cited.

\begin{abstract}
HOX genes encode an evolutionarily conserved set of transcription factors that control how the phenotype of an organism becomes organized during development based on its genetic makeup. For example, in bilaterian-type animals, HOX genes are organized in gene clusters that encode anatomic segment identity, that is, whether the embryo will form with bilateral symmetry with a head (anterior), tail (posterior), back (dorsal), and belly (ventral). Although HOX genes are known to regulate stem cell (SC) differentiation and HOX genes are dysregulated in cancer, the mechanisms by which dysregulation of HOX genes in SCs causes cancer development is not fully understood. Therefore, the purpose of this manuscript was (i) to review the role of HOX genes in SC differentiation, particularly in embryonic, adult tissue-specific, and induced pluripotent SC, and (ii) to investigate how dysregulated HOX genes in SCs are responsible for the development of colorectal cancer (CRC) and acute myeloid leukemia (AML). We analyzed HOX gene expression in CRC and AML using information from The Cancer Genome Atlas study. Finally, we reviewed the literature on HOX genes and related therapeutics that might help us understand ways to develop SC-specific therapies that target aberrant HOX gene expression that contributes to cancer development.
\end{abstract}

\section{HOX Genes}

HOX genes are master transcriptional regulators that have diverse roles from embryogenesis to carcinogenesis. The HOX genes are an evolutionary conserved family of genes that control anterior-posterior axis and dorsal-ventral anatomic development during embryogenesis. In humans there are a total of 39 HOX genes situated in clusters on four different chromosomes $(7 \mathrm{p} 15,17 \mathrm{q} 21.2,12 \mathrm{q} 13$, and $2 \mathrm{q} 31)$. These clusters are named as four HOX families: HOXA, HOXB, HOXC, and HOXD. Each family consists of 13 paralog groups with nine to eleven numbers assigned based on their sequence similarity and position within the cluster (Figure 1(a)). HOX genes contain two exons and a single intron. Exon 2 contains a 120-nucleotide sequence, known as homeobox. This homeobox encodes a 61 amino acid helixturn-helix motif known as a homeodomain (Figure 1(b)).
The protein products of the HOX genes are transcription factors that are capable of binding to specific nucleotide sequences on the DNA.

1.1. HOX Genes and Stem Cell Differentiation. SCs are multipotent cells that have the ability to self-renew or to differentiate along multiple lineages. HOX genes have been shown to play crucial roles during SC differentiation from embryonic stages of development to tissue-specific SC functions. Of the 39 HOX genes, mutations in 10 HOX genes (HOXA1, HOXA2, HOXA11, HOXA13, HOXB1, HOXB13, HOXC13, HOXD4, HOXD10, and HOXD13) have been found to cause human disorders with variations in their inheritance patterns, penetrance, expressivity, and mechanisms of pathogenesis [1]. Congenital defects caused by mutations in HOX genes support the concept that HOX gene function is crucial for SCs during development and differentiation. 


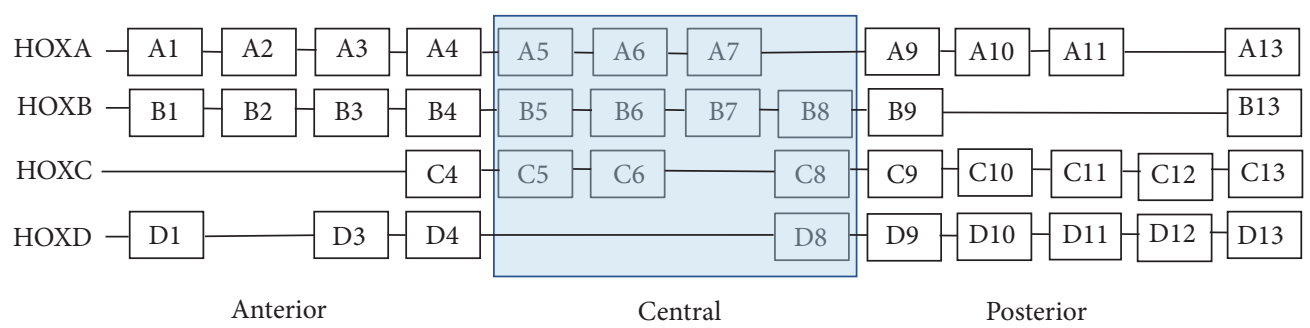

(a)

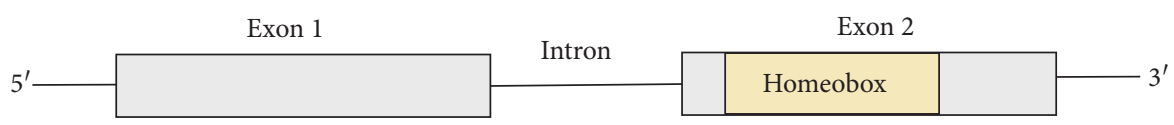

(b)

FIGURE 1: HOX genes and genome organization. (a) In humans, there are a total of 39, clustered into four families, namely, HOXA, HOXB, HOXC, and HOXD. Each family consists of 13 paralogous groups with nine to eleven numbers assigned based on their sequence similarity and position within the cluster. (b) HOX genes have two exons and 1 intron. Exon 2 has a 120 -nucleotide sequence, called a Homeobox that encodes a 61 amino acid HOX protein.

Therefore, we reviewed the published literature for the role of HOX genes during differentiation of three main types of SC, namely, (i) embryonic SCs, (ii) adult SCs (hematopoietic SCs, colonic SCs, and mesenchymal SCs), and (iii) induced pluripotent SCs.

1.1.1. HOX Genes and Embryonic Stem Cell Differentiation. Embryonic stem cells (ESCs) are obtained from the inner cell mass of the blastocyst. ESCs are pluripotent cells that can give rise to most cell types except the placenta and umbilical cord. Retinoic acid (RA) signaling regulates HOX gene expression in ESCs during embryonic development. In adult neurogenesis, ESCs treated with RA almost exclusively differentiate into neurons and develop a HOX-related expression profile [2]. Retinoic acid response elements (RAREs) are found in regulatory regions of many $\mathrm{HOX}$ genes $[3,4]$. In mice, RAREs are found in Hoxa1, Hoxa4, Hoxb1, Hoxb4, and Hoxd4 [5-14]. Several HOX genes have been found to be strongly upregulated during differentiation in the presence of RA [15]. RA receptor $\gamma(\operatorname{RAR} \gamma)$ was found to be essential for RA-induced HOX gene transcriptional activation in ESCs. Deletion of its binding site in the Hoxal enhancer attenuates transcriptional and epigenomic activation of both Hoxa and Hoxb gene clusters. It was reported that RA/RAR $\gamma$ signaling is critical for the removal of histone methylation occurring on the amino terminal tail core of the core histone H3 (H3K27me3) from activated Hox genes during ESC differentiation [16]. The entire Hox cluster is actively repressed in ESCs by polycomb repressor complexes and plays key regulatory roles during their differentiation to multipotent progenitors in developing tissues [17]. As ESCs differentiate into different lineages, Hox gene clusters become activated in a controlled and sequence-specific manner $[17,18]$. It has been shown that timely induction of Hoxb1 in ESCs results in the differentiation of neuronal SCs and neural progenitors of distinct posterior identities [19]. It is well-known that Hoxb4 overexpression in ESCs confers long-term repopulating ability to ESC-derived hematopoietic stem cells (HSCs). Furthermore, Hoxb4 acts as a master regulator of
ESC differentiation into HSCs by directly targeting multiple essential hematopoietic transcription factors and epigenetic factors [20]. Overall, these results show that complex regulatory mechanisms exist through which Hox genes are expressed in ESCs and function during differentiation.

1.1.2. HOX Genes and Adult Stem Cells. Adult SCs, also referred to as somatic or tissue-specific SCs, give rise to different cell types that are specific to each tissue type or organ in which they reside. HOX genes are crucial for the maintenance and functioning of adult SCs. Here, we focus on three types of adult SCs: hematopoietic SCs that generate entire blood cell lineages, colonic SCs that reside at the base of the normal crypt and are responsible for colonic tissue renewal and proper functioning of the colon, and mesenchymal SCs isolated from the stroma and that generate various differentiated cell types from bone, cartilage, and fat cells.

(1) HOX Genes and Hematopoietic Stem Cells. Hematopoietic stem cells (HSCs) are generally found in the bone marrow but can also be isolated from the peripheral blood, umbilical cord blood, and fetal liver. HOX genes are expressed in HSCs and progenitors in a lineage-specific and differentiation stage-restricted manner. For example, HOXB3, HOXB4, and HOXA9 are abundantly expressed in HSCs, whereas HOXB8 and HOXA10 are expressed only in myeloid committed cells. Recent studies showed that HOXA family genes are mostly expressed in the myeloid cells, HOXB family genes are mostly expressed in the erythroid cells, and HOXC family genes are commonly seen in the lymphoid cells. HOXD family genes are not expressed during hematopoiesis despite their similarities to other HOX gene clusters [21-24]. Since specific HOX genes are essential for SC differentiation into specific blood cell types, we present a diagram of all known HOX genes associated with hematopoiesis (Figure 2).

1.1.3. HOXA5. HOXA5 overexpression in bone marrow CD34+ SCs and cord blood CD34+ CD38- cells resulted in 


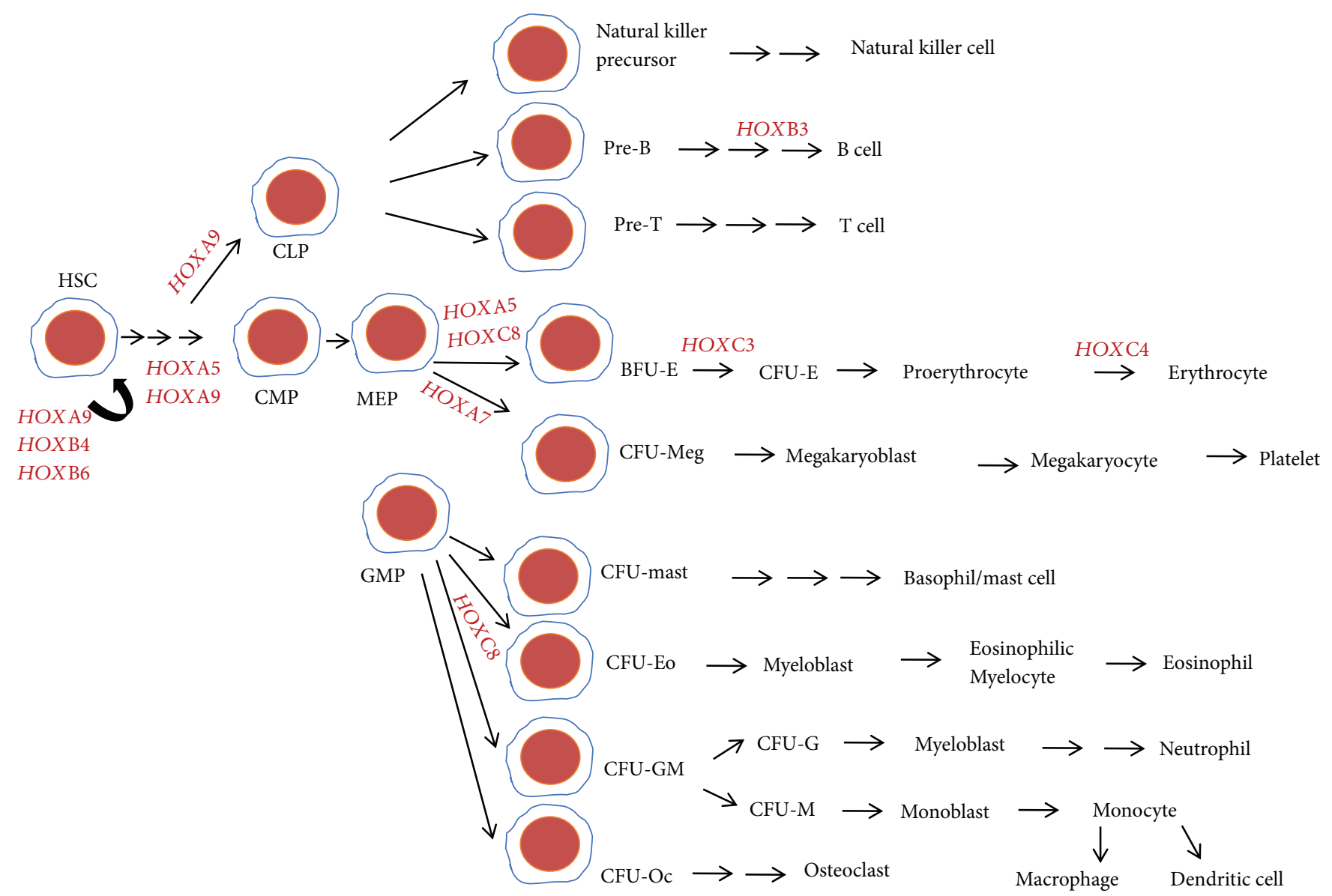

FIgURE 2: HOX gene expression during hematopoiesis. The hematopoietic stem cell (HSC) is a multipotent stem cell that has the ability to give rise to common lymphoid progenitor (CLP) and common myeloid progenitor (CMP) cells. HOXA9, HOXB4, and HOXB6 are known to be expressed in HSC and regulate HSC self-renewal. HOXA5 and HOXA9 are involved in the proliferation and differentiation of HSC to CMP, and HOXA9 regulates the differentiation of HSC into CLP. HOXB3 is expressed during the differentiation of pre-B cells into B cells. HOXA5 and HOXC8 are expressed during erythroid differentiation of megakaryocyte-erythrocyte progenitors (MEP) whereas HOXA7 is expressed during megakaryocyte differentiation. HOXC3 and HOXC4 are crucial during erythroid lineage differentiation. HOXC8 is shown to play a regulatory role during the differentiation of granulocyte-monocyte progenitor (GMP) cells. HSC: hematopoietic stem cells; CMP: common myeloid progenitor; CLP: common lymphoid progenitor; MEP: megakaryocyte-erythrocyte progenitor; GMP: granulocyte-monocyte progenitor; BFU-E: erythroid burst-forming units; CFU-E: erythroid colony-forming unit; CFU-Meg: megakaryocyte colony-forming unit; CFU-mast: mast colony-forming unit; CFU-Eo: eosinophil colony-forming unit; CFU-GM: granulocyte-monocyte colony-forming unit; CFU-Oc: osteoclasts colony-forming unit.

a significant shift in myeloid differentiation [25]. When HOXA5 was overexpressed in HSCs, erythroid progenitors (burst-forming unit-erythroid BFU-E) were significantly decreased in frequency among all progenitors, with no reduction in total colony-forming unit (CFU) numbers [25]. Similarly, the overexpression of HOXA5 inhibited erythroid differentiation of K562 cells [26]. In contrast, the knockdown of HOXA5 in human bone marrow cells resulted in the inhibition of granulocytic/monocytic hematopoiesis and increased erythroid progenitors [26]. Overall, these studies showed that HOXA5 is crucial for the balance between myeloid and erythroid differentiation.

1.1.4. HOXA7. Hoxa7 knockout mice showed reduced megakaryocytic/erythroid progenitors (MEP) and exhibited reticulocytosis and thrombocytopenia without anemia [27], suggesting that $H O X A 7$ is required for MEP differentiation.
1.1.5. HOXA9. HOXA9 is one of the most abundant HOX genes in HSCs. HOXA9 is downregulated during HSC differentiation [24, 28]. Hoxa9 knockout mice displayed marked lymphopenia (low levels of lymphocytes in the blood) and substantial reductions of common lymphoid progenitors (CLPs) and lymphoid precursors. In addition, significant reduction of common myeloid progenitors (CMPs) and granulocyte/monocyte progenitors (GMPs) was observed upon Hoxa9 knockout in vivo [27]. Hoxa9 knockout mice also showed a reduction in the number of total leukocytes [29], and the loss of expression of Hoxa9 impaired the proliferating and repopulating ability of HSCs [30]. HOXA9 thus appears to regulate HSC proliferation, self-renewal, and myeloid and lymphoid differentiation.

1.1.6. HOXA10. HOXA10 overexpression in human cord blood and fetal liver CD34+ cells resulted in a significant 
production of blast cells (undifferentiated blood cells, commonly seen in acute leukemia) and myelopoiesis concomitant with a complete block of erythroid differentiation and a severe reduction in $\mathrm{B}$ cell development [31]. Thus, these findings suggest that the regulation of HOXA10 expression is crucial for preventing abnormal development and differentiation of HSCs.

1.1.7. HOXB3. In mice, the overexpression of Hoxb3 blocked $\mathrm{B}$ and $\mathrm{T}$ cell differentiation and caused a delay in myeloid precursor proliferation [32], whereas the knockout of Hoxb3 in mice at 6 months of age caused significant impairment of $B$ cell development in the bone marrow [33].

1.1.8. HOXB4. HOXB4 is known to enhance primitive hematopoietic cell growth by increasing self-renewal without affecting homeostatic control of HSC population size or of the rate of HSC production. The retention of full lymphomyeloid repopulating potential and enhanced in vivo regenerative potential demonstrates the feasibility of achieving significant ex vivo expansion of HSCs without functional impairment [34-39]. Hoxb3 and Hoxb4 double-knockout mice showed defects in endogenous hematopoiesis with reduced cellularity of HSC regeneration. Hoxb3 $3^{-} / H_{o x} b 4^{-}$ mice showed reduction in hematopoietic progenitor numbers without perturbing lineage commitment [40].

1.1.9. HOXB6. Hoxb6 overexpression in mice resulted in HSC and myeloid progenitor cell expansion but inhibited erythropoiesis and lymphopoiesis [41]. Upregulation of HOXB6 is often seen in acute myeloid leukemia (AML). Cytogenetic analysis of a subset of HOXB6-induced AMLs revealed recurrent deletions of chromosome band 2D-E4, a region frequently deleted in HOXA9-induced AMLs. The biologic effects of $H O X B 6$ were seen to be largely dependent on DNA binding but they were independent of direct interaction of PBX1 [41]. The knockout of Hoxb6 resulted in an increase in early erythroid progenitors in murine bone marrow and fetal liver cells [42]. Thus, HOXB6 is critical not only for HSC self-renewal and maintenance but also for regulatory balance between lymphoid and myeloid differentiation.

1.1.10. HOXC3. An antisense oligonucleotide against Hoxc3 inhibited the formation of colony-forming units (CFUs) of erythroid-derived colonies without any changes in size or degree of hemoglobinization. Early erythroid burst-forming unit colonies or myeloid colonies were not affected, demonstrating that Hoxc3 is involved in an early step in proliferation of the erythroid colony-forming unit subset of progenitor cells [43].

1.1.11. HOXC4. The enforced expression of HOXC4 in human CD34+ cells induced a significant increase in the number of erythroid colonies compared with granulocyte/ macrophage colony-forming units (CFU-GM), without perturbing, at least in vitro, the maturation program of these cells. On the other hand, HOXC4 overexpression did not induce any skewing in the colony types derived from the myeloid lineage [44].
1.1.12. HOXC8. A significant reduction in the number of erythroid burst-forming units (BFU-E) and in CFU-GM occurred in Hoxc8 null mice, although the peripheral blood cell counts were normal [45] suggesting that HOXC8 plays a role during MEP (megakaryocyte-erythroid progenitor) differentiation into BFU-E and GMP differentiation into CFU-GM.

(1) HOX Genes and Colonic Stem Cells. We previously showed that normal colonic SCs are found at the base of the normal human colon crypt and can be isolated using SC markers such as aldehyde dehydrogenase (ALDH1), ALCAM (CD166), and LGR5 [46-48]. The overpopulation of colonic SCs drives colorectal cancer (CRC) development $[47,48]$. We studied the expression of HOX genes in normal colonic SCs by microarray profiling. Our analysis showed that HOXA4, HOXA9, and HOXD10 are expressed more in colonic SCs than in proliferating cells or differentiating crypt cells [49]. Further studies showed that HOXA4 and HOXA9 are enriched in SCs during CRC development and that the dysregulation of HOXA4 and HOXA9 expression promotes self-renewal and proliferation of colonic SCs [50] (Figure 3). The siRNA knockdown of HOXA4 and HOXA9 in colon cancer cell lines SW480 and HT29 reduced proliferation and sphere-forming ability of colon SCs [50] thus suggesting regulatory roles of $\mathrm{HOX}$ genes during colon SC maintenance and differentiation.

(2) HOX Genes and Mesenchymal Stem Cells. Mesenchymal stem cells (MSCs) isolated from the umbilical cord blood express HOXA9, HOXB7, HOXC10, and HOXD6, whereas bone marrow-derived MSCs express HOXB7 and HOXD6 [51]. HOXC10 was found to be differentially expressed in amnion- and decidua-derived MSCs [51]. HOX genes, particularly HOXA9, HOXB7, HOXC10, and HOXD8, were used as biomarkers to distinguish between MSCs derived from unrestricted somatic stem cells and cord blood [51]. A study by Woo et al. [52] showed that the expression of HOXC13 increased whereas HOXD13 expression decreased as bone marrow-derived MSCs differentiated into osteoblasts during osteogenesis. Taken together, these findings indicate that distinct expression patterns of HOXA5, HOXA10, HOXB6, HOXB7, HOXC4, HOXC6, HOXC8, HOXC9, HOXC10, HOXD3, and HOXD8 exist in MSCs derived from different human sources [52]. Hoxb2, Hoxb5, Hoxb7, and Hoxc4 genes were found to regulate self-renewal and differentiation of murine MSCs [53].

HOX genes have been shown to play critical roles during osteogenesis of human MSCs. Histone demethylase KDM6B controlled HOX expression by removing histone 3K27 trimethylation (H3K27me3) and reduced KDM6B significantly by reducing osteogenic differentiation and increasing adipogenic differentiation [54]. The role of HOX genes during differentiation of human vascular wall-resident CD44+ multipotent stem cells (VW-MPSCs) was also studied [55]. VW-MPSCs are capable of differentiating into pericytes and smooth muscle cells. This study demonstrated that the expression of HOXB7, HOXC6, and HOXC8 is differentially expressed in VW-MPSCs as compared to terminally 


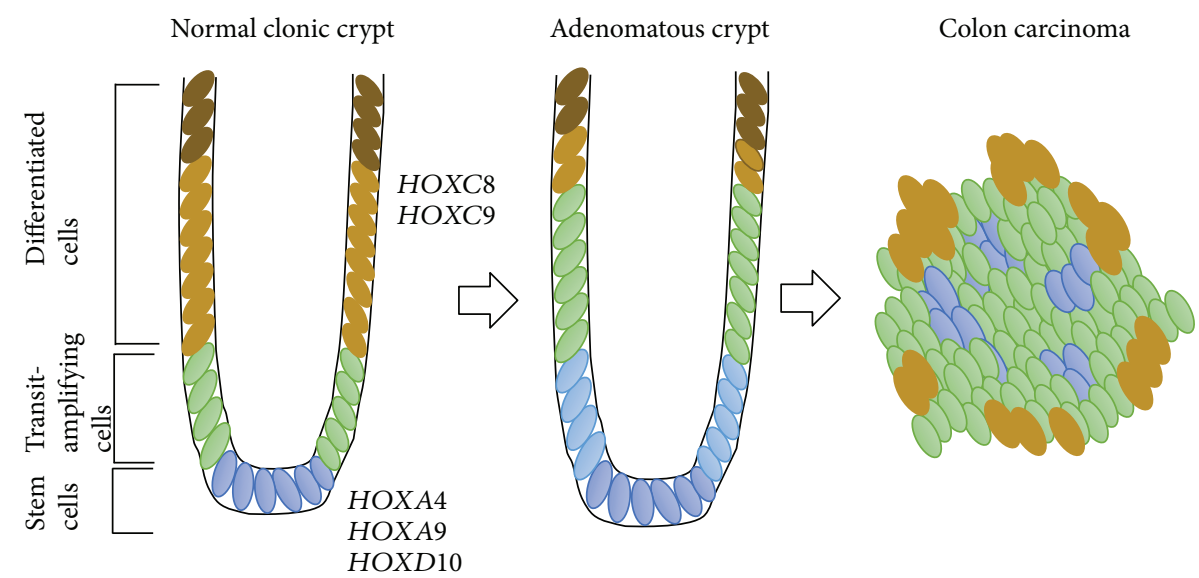

FIgURe 3: HOX gene expression during colonocyte differentiation. Normal colonic crypts consist of mainly three types of cells based on their location in the crypt. Colon stem cells (SCs) reside at the base of the colonic crypt (shown in blue color). HOXA4, HOXA9, and HOXD10 are expressed in colonic SCs and regulate colonic crypt SC differentiation $[49,50]$. SCs generate transit-amplifying cells (shown in green color) that are actively proliferating and differentiating (shown in gold-bronze yellow color) as they move up the axis in the colonic crypt. Finally, fully differentiated or terminally differentiating cells are found at the top of the crypt (shown in brown color). Studies have shown that HOXA family genes are expressed mostly in proliferating colonic cells, and HOXC family genes are expressed in differentiating cells [68]. HOXB and HOXD family genes are expressed throughout the colonic crypts [68]. In colon tumors, the dysregulation of HOXA4 and HOXA9 in colon SCs caused aberrant self-renewal and proliferation, contributing to colon carcinoma [50]. HOXC8 and HOXC9 are expressed in the differentiating cells in the colonic crypt [68].

differentiated human aortic smooth muscle cells, endothelial cells, and undifferentiated pluripotent ESCs. The knockdown of HOX genes in VW-MPSCs reduced their sprouting capacity and increased their levels of smooth muscle markers, transgelin and calponin, as well as histone H1. In addition, changes in methylation patterns of the TAGLN promoter were observed [55]. Overall, this study suggested a role for HOX genes in regulating differentiation of human VWMPSC into smooth muscle cells via epigenetic mechanisms. The results of this study will help us understand VWMPSC-dependent vascular disease processes such as neointima formation and tumor vascularization [55].

1.1.13. HOX Genes and Induced Pluripotent Stem Cells. Induced pluripotent stem cells (iPSCs) are cells that are engineered in the lab by converting tissue-specific adult SCs into cells that possess ESC-like properties. iPSCs, like ESCs, did not express HOX genes [56]. Although suppression of HOX gene expression was observed in iPSCs, transient $\mathrm{WNT} / \beta$-catenin signaling triggered the activation of the CDX/HOX pathway, which in turn conferred a hematogenic posterior mesoderm phenotype to differentiating human iPSCs [57].

\section{HOX Genes and Cancer}

In recent years, it has been shown that HOX genes are not only responsible for proper embryonic development but they are also associated with cancer development [58]. In the next section of this review, we focus on the role of HOX genes in cancer development, particularly colorectal cancer (CRC) and acute myeloid leukemia (AML).
2.1. HOX Genes in CRC. Aberrant expression of HOX genes is seen in CRC $[49,50,58,59]$. We previously reported that HOXA4, HOXA9, and HOXD10 are expressed in normal colonic SCs and dysregulation of HOX genes leads to aberrant SC differentiation, contributing to CRC development and growth. Furthermore, we showed that HOXA4 and HOXA9 genes promote self-renewal and proliferation of colonic SCs, contributing to CRC development $[49,50]$.

In this review, we also evaluate the role of HOX genes during CRC development using The Cancer Genome Atlas (TCGA) database. Tumor samples were collected from newly diagnosed patients (i) with colon or rectum adenocarcinoma (ii) undergoing surgical resection, and (iii) having received no prior treatment for their disease, including no chemotherapy and no radiotherapy. All cases were collected regardless of surgical stage or histologic grade. Cases were staged according to the American Joint Committee on Cancer (AJCC) staging system. Each frozen tumor specimen had a companion normal tissue specimen which could be blood/ blood components, adjacent normal tissue taken from greater than $2 \mathrm{~cm}$ from the tumor, or previously extracted germline DNA from the blood [60]. Our analysis showed that HOXB9 was the most upregulated gene at all stages (Figure 4). HOXB6 and HOXB8 expression increased from stages I to IV but dramatically decreased at stage IVA. Interestingly, the expression of HOXB6 and HOXB8 was increased during stages I and II and decreased at stage III but again increased at stage IV (Figure 4(f)).

HOXD family gene expression increased at stage IVA compared to all other stages of CRC (Figure 4). Our analysis showed that there is no difference in HOX gene expression based on gender (Figure 5). When we compared TCGA datasets for HOX gene expression in CRC to overall survival, 


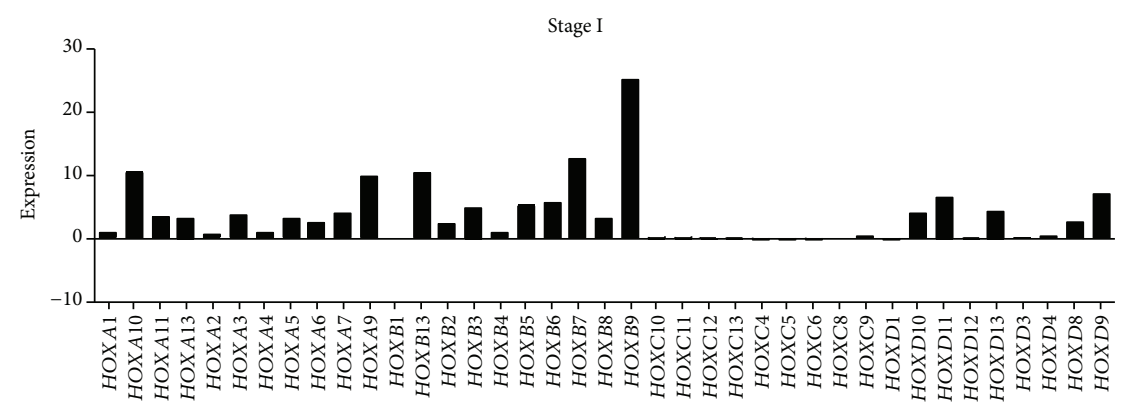

(a)

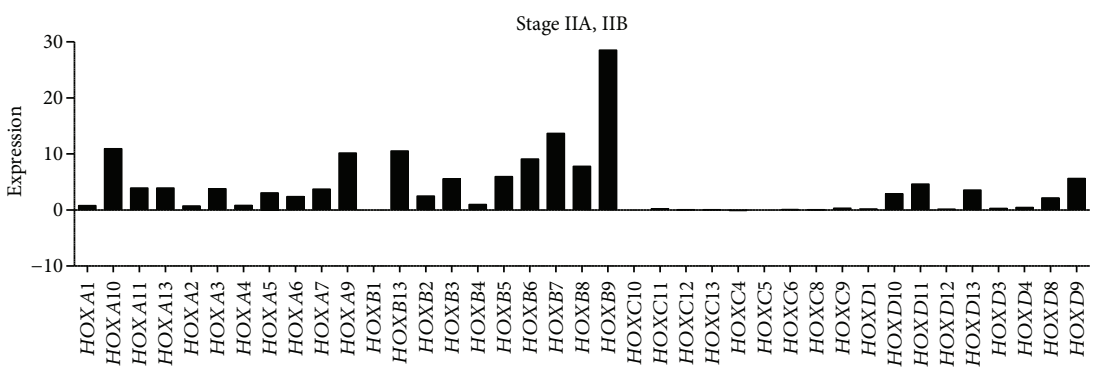

(b)

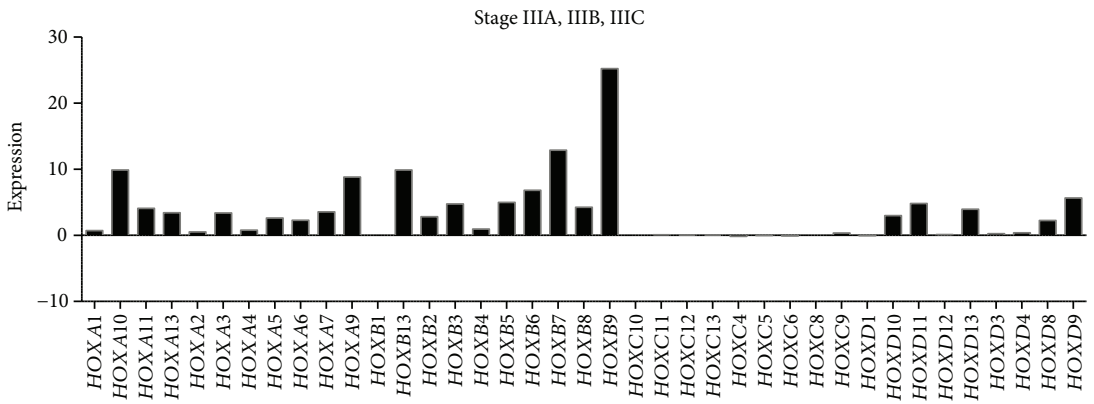

(c)

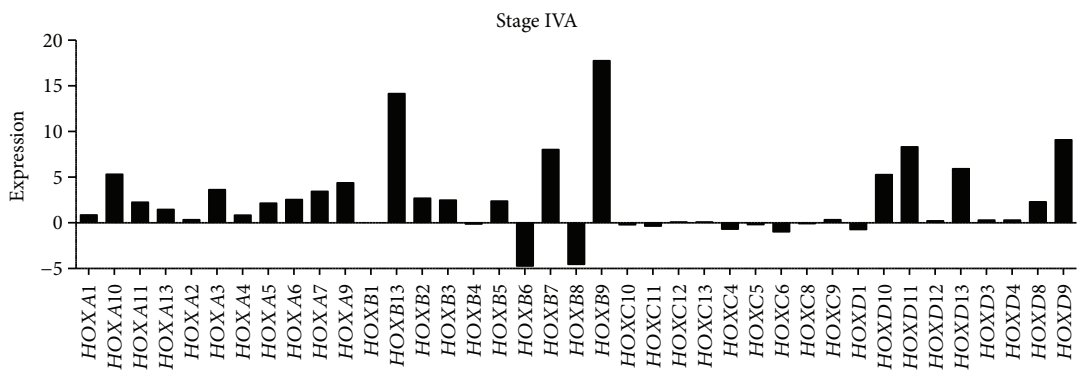

(d)

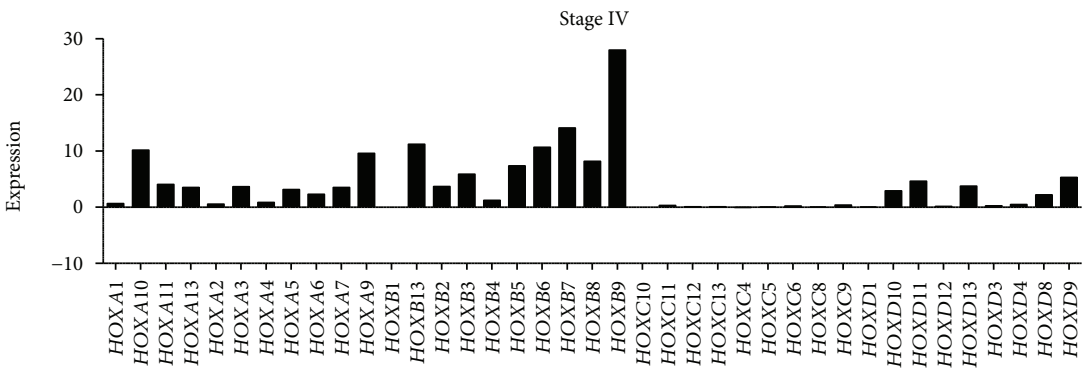

(e)

FIgURe 4: Continued. 


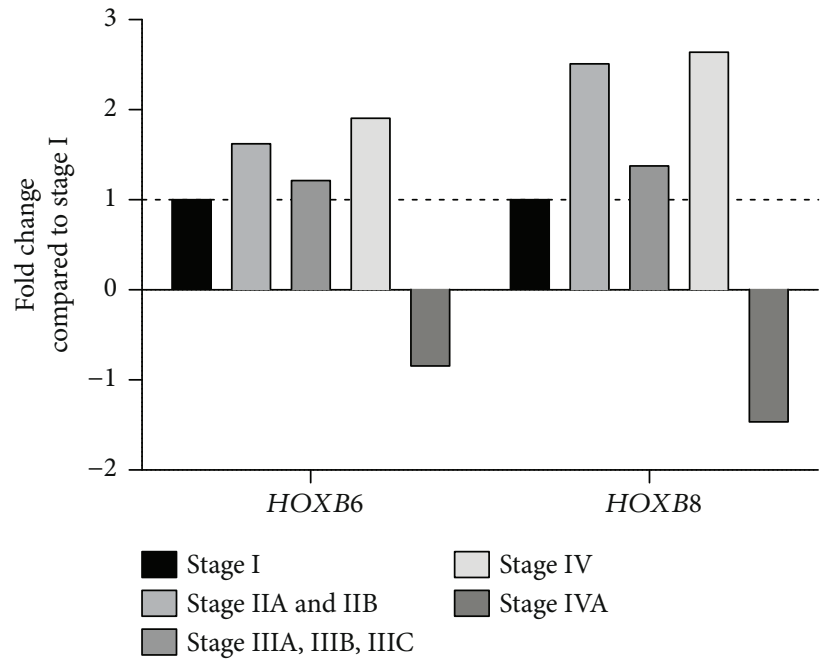

(f)

FIGURE 4: HOX gene expression during different stages of CRC. RNA sequencing data for CRC patients obtained from The Cancer Genome Atlas (TCGA) for HOX gene expression (normalized FPKM) and analyzed based on different stages of CRC. We studied (a) 55 cases for stage I, (b) 102 cases for stage IIA and IIB combined, (c) 66 cases reporting stage IIIA, IIIB, and IIIC, (d) 39 samples for stage IV, and (e) 4 cases for stage IVA. (f) Fold changes in the expression of HOXB6 and HOXB8 are shown for stages II, III, IV, and IVA compared to stage I.

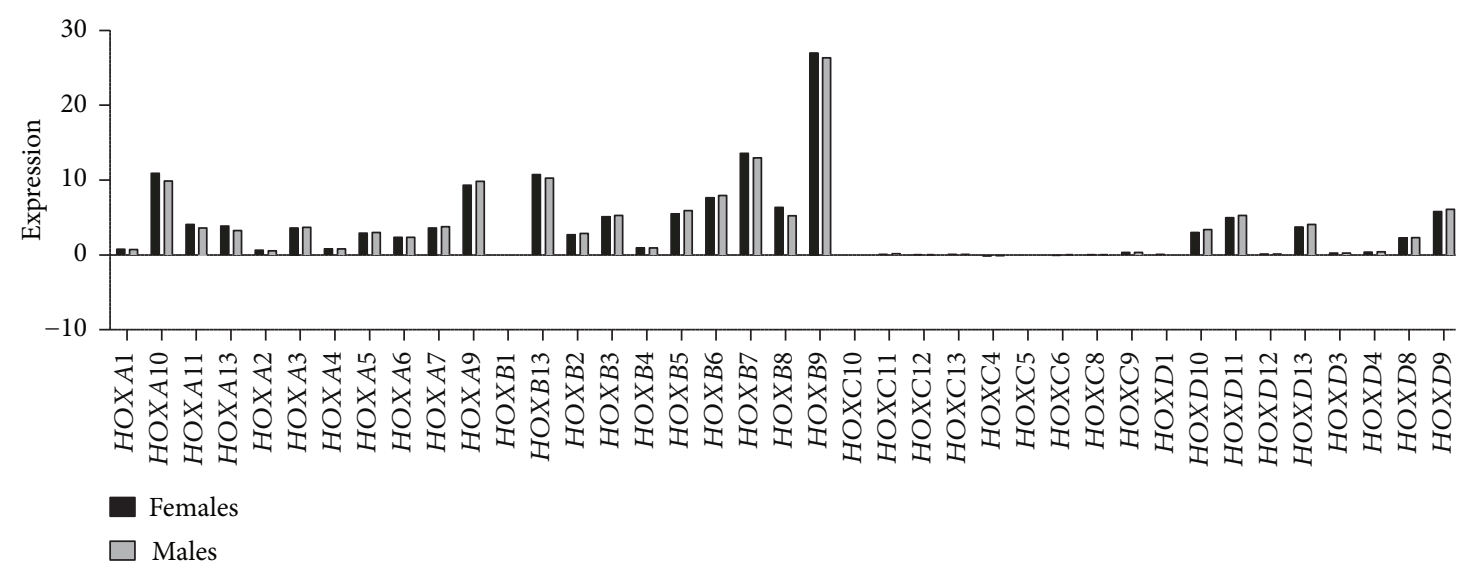

Figure 5: Gender-based HOX gene expression in CRC. The Cancer Genome Atlas (TCGA) was used to analyze gender-based differences in HOX gene expression in CRC patients. Normalized FPKM expression of HOX genes is plotted for male versus female CRC patients.

increased $H O X B 13$ was found to be associated with decreased survival (data not shown). It was reported earlier that missense germline $H O X B 13$ mutations, most commonly in G84E (HOXB13 p. Gly84Glu), are associated with earlyonset prostate cancer and possibly associated with breast cancer and colorectal cancer [61-63]. Unlike HOXB13, increased HOXB8 expression was associated with increased survival. We observed similar trends in expression of other HOX genes, whereby changes in the level of expression was correlated with improved survival and greater in tumor than tumor-free CRC cases (discussed below).

Next, we analyzed HOX expression based on their family gene clusters. Among all HOX families, the HOXB family showed the highest expression in CRC. In the HOXB family, HOXB9, HOXB8, HOXB6, HOXB13, HOXB, and HOXB7 were all overexpressed in CRC (Figure 6(a)). The HOXA family showed the next highest expression. In the HOXA family, HOXA9 and HOXA10 showed higher expression than the remaining HOXA family genes (Figure 6(b)). Among HOXD family members, HOXD10, HOXD11, HOXD13, and HOXD9 showed increased expression compared to the others (Figure 6(c)). The HOXC family of genes showed the least expression compared to HOXA, HOXB, and HOXD (Figure 6(d)).

We further assessed HOX genes as a function of overall patient survival. Because we previously found that HOXA4 and HOXD10 are expressed in crypt SCs, we measured HOXA4 and HOXD10 levels in CRC cases $(n=220)$ based on high versus low expression (cutoff at 25 th percentile). HOXA4 and HOXD10 high-expressing cases $(n=110)$ of CRC patients showed overall low survival rates. Increased HOXD10 expression was found to be significantly associated with poor overall survival in CRC (Figure 7(a)). HOXD10 high expressers showed only a $15 \%$ survival rate versus $55 \%$ 


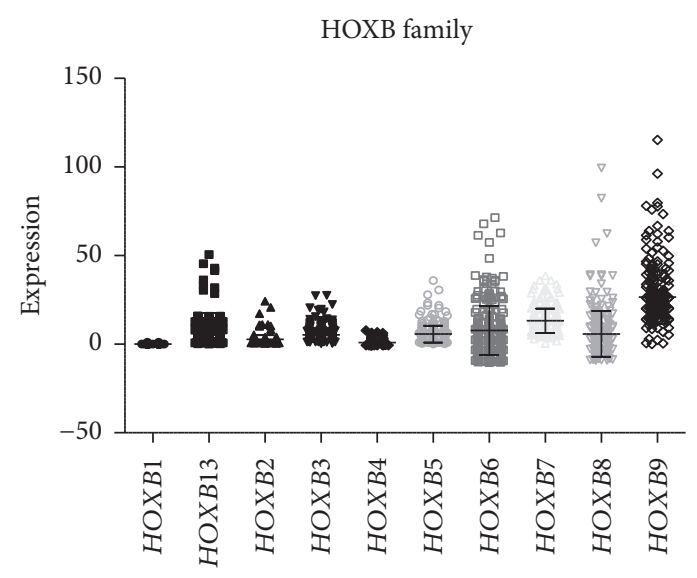

(a)

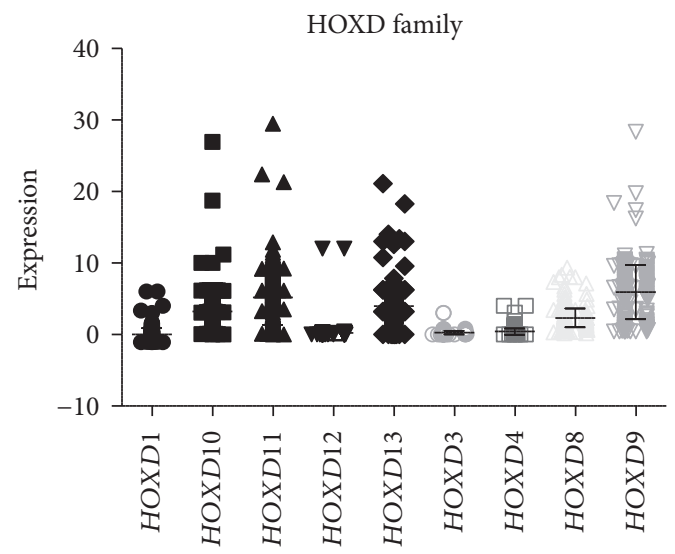

(c)

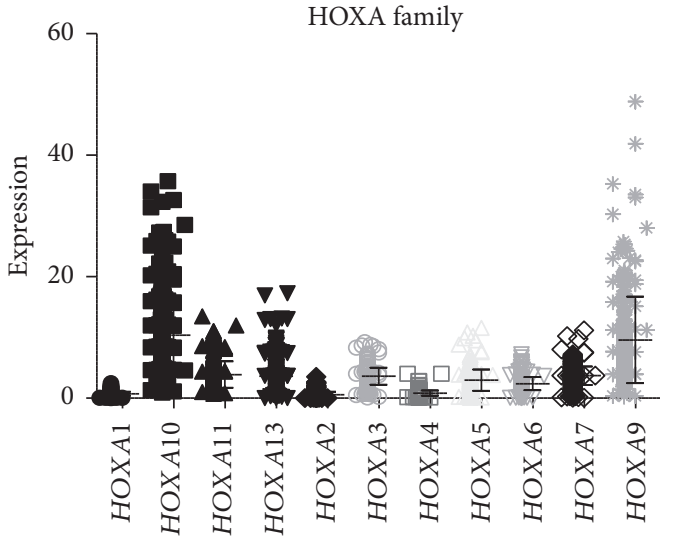

(b)

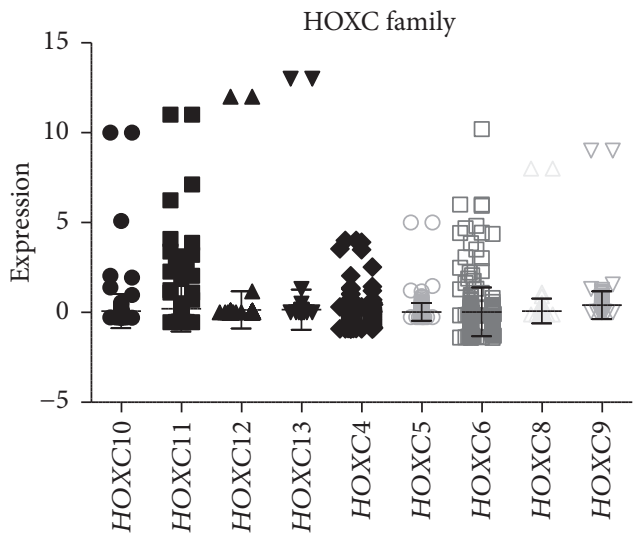

(d)

FIgURE 6: HOX family gene expression in CRC. (a) HOXB family gene expression, (b) HOXA family genes, (c) HOXD family genes, and (d) HOXC family genes were analyzed using TCGA RNAseq for $n=273$ patient samples. $y$-axis denotes normalized FPKM values for HOX gene expression.

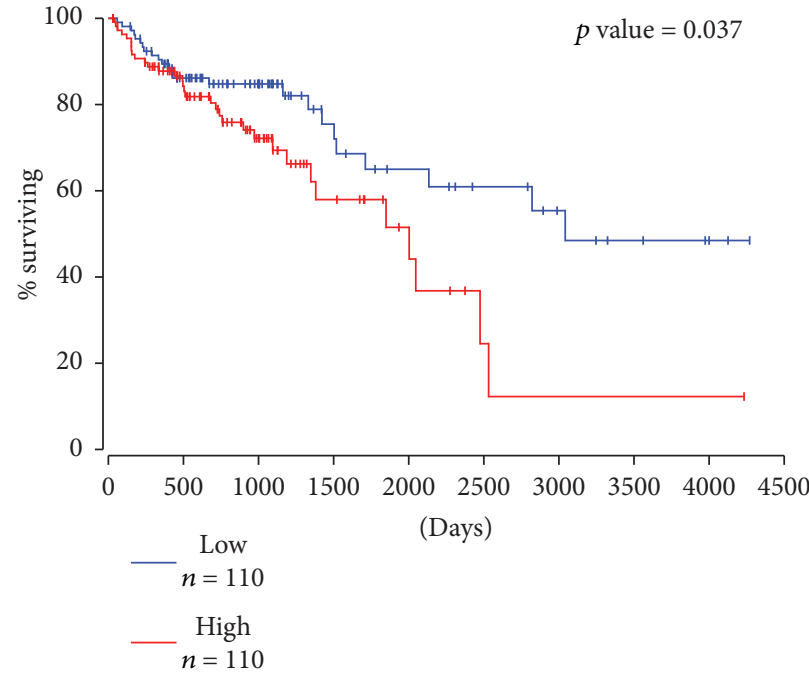

(a)

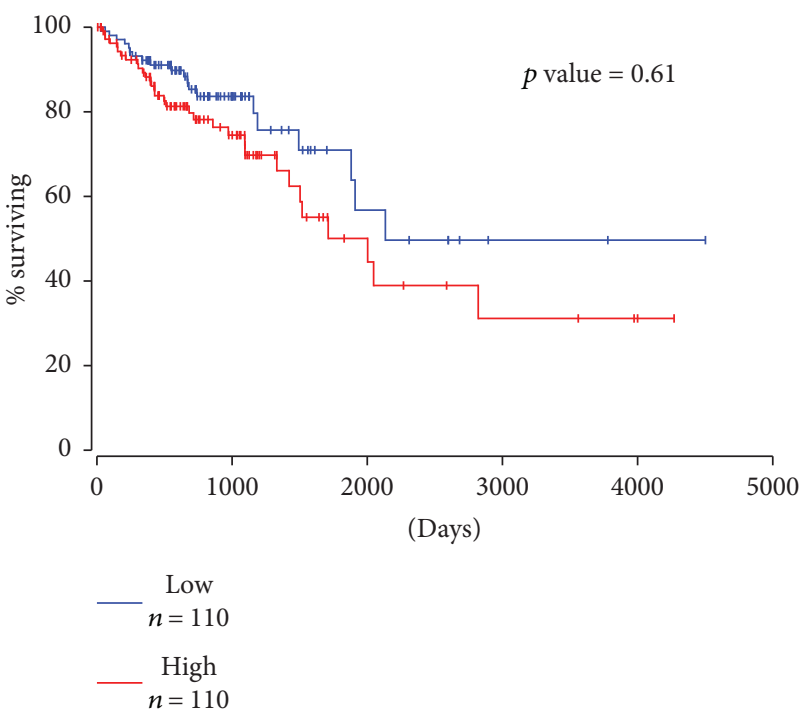

(b)

FIGURE 7: Overall survival analysis for HOXA4 and HOXD10 in colorectal cancer. Kaplan-Meier survival analysis of the 220 colorectal cancer patients using TCGA dataset. (a) HOXD10 and (b) HOXA4 survival analysis was performed for CRC patients with a cutoff value of 25th percentile. Credits: http://www.oncolnc.org. 
survival rate of $H O X D 10$ low expressers (Figure $7(\mathrm{a})$ ). HOXA4 high expressers showed about a $30 \%$ survival rate as compared to a $50 \%$ survival rate of $H O X A 4$ low expressers (Figure $7(\mathrm{~b})$ ). We also analyzed the association of HOXA9 with the SC marker ALDH1A1 in CRC patients using TCGA database. A significant positive correlation was observed between HOXA9 and ALDH1A1 in CRC $(r=0.12, P=0.048)$ (Figure 8(a)). Retinoid receptors, $R X R B$, showed negative significant correlation with ALDH1A1 $(r=-0.13, P=0.026)$ (Figure 8(b)). Another stem cell marker, ALCAM (also known as CD166), was correlated with HOX gene expression in CRC. Expression of HOXA4 negatively correlated with ALCAM in CRC patients $(r=-0.14, P=0.024)$ (Figure 8(c)). HOXA9 was positively correlated with ALCAM $(r=0.18, P=0.0027)$ (Figure $8(\mathrm{~d}))$. HOXD10 showed significant negative correlation with ALCAM $(r=-0.18, P=0.003)$ (Figure $8(\mathrm{e})$ ) whereas $H O X B 8$ showed a significant positive correlation with ALCAM ( $r=017, P=0.006$ ) (Figure 8(f)).

Other published reports on the involvement of HOX genes in CRCs were reviewed [49]. The expression of HOXD8 is downregulated in clinical CRCs compared to normal colon tissues, and the stable expression of HOXD8 in CRC cells significantly reduced cell proliferation, anchorage independent-growth, and invasion. Apoptotic inhibitor genes such as STK38 and MYC were found to be negatively associated with HOXD8 in analyses using The Cancer Genome Atlas (TCGA). Mansour and Senga demonstrated the ability of HOXD8 to activate caspases 6 and 7 and cleave PARP, thus enhancing apoptosis of CRC cells [64]. A study by Chen et al. showed that HOXD3 is upregulated in human RKO colon cancer cells. The inhibition of HOXD3 by shRNA in RKO cells significantly decreased proliferation and colony formation and increased apoptosis of RKO colon cancer cells. HOXD3-inhibited cells were arrested in the G2 phase of the cell cycle [65]. Among HOXD clusters, induction of the expression of HOXD8, HOXD9, HOXD10, or HOXD12 induces growth arrest and neuronal differentiation with downregulation of cell cycle-promoting genes and upregulation of differentiation genes. Other HOXD genes such as HOXD1, HOXD3, HOXD4, HOXD11, and HOXD13 had no effects or only partial effects on neuroblastoma cell proliferation or differentiation [66]. These findings suggest that $\mathrm{HOXD}$ genes have distinct functions in the induction of cancer cell differentiation. Other HOX genes, such as HOXB6, HOXB8, HOXC8, HOXC9, and CDX1 were also found to be dysregulated in human CRC development [67]. Furthermore, the HOXA family gene was abundantly expressed in colonic adenocarcinoma cells [68]. Overall, these findings suggest that HOX genes play key regulatory roles during maintenance of normal colon SC differentiation and that aberrant expression is associated with CRC development.

2.1.1. CDX1/CDX2 Genes in CRC. Another set of Hox genes, the Cdx genes (also classified as ParaHox genes or caudalrelated homeobox genes), is expressed in a wide variety of organisms [69]. Three Cdx genes, $C d x 1, C d x 2$, and $C d x 4$, exist in mouse and humans (CDX1, CDX2 and CDX4) and regulate anterior-posterior patterning [70, 71]. The CDX genes are not located in a homeobox cluster, $C D X 1$ is located on human chromosome $5 q 31-33, C D X 2$ gene is on chromosome $13 \mathrm{q} 12$, and $C D X 3$ is on Xq13.2. In mice, $C d x 1$ and $C d x 2$ are important for gastrointestinal tract development. $C D X 1$ and $C D X 2$ are also actively expressed in adult intestinal epithelium and are involved in the regulation of enterocyte proliferation and differentiation as well as WNTmediated beta-catenin signaling [70, 72, 73]. Moreover, reduced expression of $C D X 2$ appears to contribute to the development of intestinal neoplasia and is a prognostic biomarker for stage II and stage III colon cancer by identifying high-risk patients who might benefit from adjuvant chemotherapy [74-76].

2.1.2. HOX Genes in AML. Studies of AML patients show that many cases $(\sim 35 \%)$ have mutations in type III receptor tyrosine kinase FLT3 and that HOXB2 and HOXB3 are increased in AML patients with FTL3-ITD (internal tandem duplication) mutation. The overexpression of Hoxb2 and Hoxb3 in mouse pro-B cells resulted in decreased FLT3-ITDdependent cell proliferation, reduced colony formation, and increased apoptosis, suggesting that HOXB2 and HOXB3 are regulators of FLT3-ITD-driven AML [77]. Several studies also showed that HOX genes promote AML development by forming chimeric fusions with other genes. Fusion of the nucleoprotein NUP98 with HOXA9 via chromosome translocation $\mathrm{t}(7 ; 11)$ (p15s;p15) causes development of AML [78]. Mice overexpressing Hoxa9 and Meis1a induced growth factordependent AML in less than 3 months. However, the overexpression of Hoxa9, Mesila, or Pbx1b alone, or in combination with Hoxa9 and $P b x 1 b$, failed to transform these cells acutely within 6 months posttranslation [79]. NUP98-HOXA9 fusion genes induced long-term proliferation and blocked differentiation of human CD34+ HSCs [80]. Recent data showed that mixed lineage leukemia (MLL) is crucial for NUP98-HOXA9 leukemia initiation [81]. We analyzed the TCGA dataset and did overall survival analysis for HOXA9 in AML patients $(n=74)$ and found that HOXA9 high expressers had a $20 \%$ survival rate compared to HOXA9 low expressers which had a $50 \%$ survival rate (Figure 9 ).

2.2. Cancer Stem Cells. Cancer stem cells (CSCs) are multipotent and have the ability to undergo both self-renewal and differentiation. We and others have shown that CSCs are the root cause of cancer development [46, 47]. These CSCs are resistant to chemotherapy and radiation. Previously, we identified HOXA4, HOXA9, and HOXD10 signatures for normal colonic SCs and that these HOX genes are upregulated during CRC development. Indeed, HOXA4 and HOXA9 were found to have roles in self-renewal and proliferation of colonic SCs that contribute to CRC development $[49,50]$. Moreover, HOXA9 is known to have a pivotal role in HSC self-renewal and that the upregulation of HOXA9 leads to AML [82]. Another report showed that $m i R-375$ inhibited the proliferation of CSCs and tamoxifen resistance by targeting $\mathrm{HOXB3}$ in human ER-positive breast cancers [83].

2.3. HOX Genes as Biomarkers. HOX genes have been used as markers to distinguish stromal populations from different 


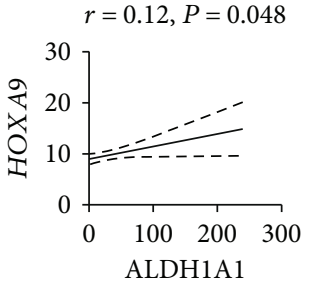

(a)

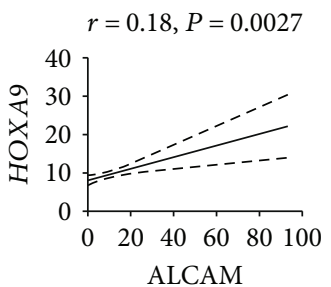

(d)

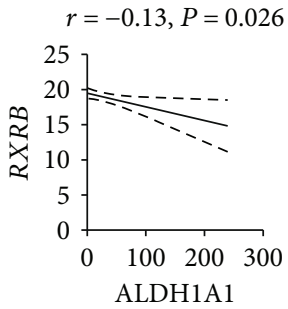

(b)

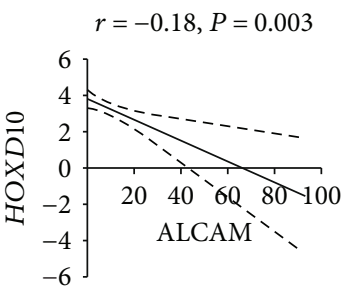

(e)

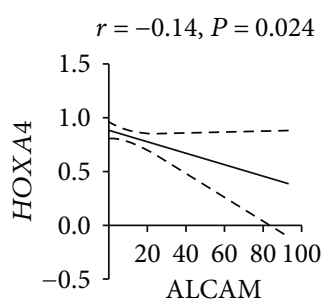

(c)

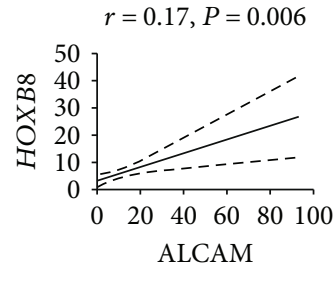

(f)

FIGURE 8: Correlation analysis of HOX genes and retinoid receptors with stem cell markers in colorectal cancer. (a) The expression of $H O X A 9$ and ALDH1A1 (SC marker) in colorectal cancer (CRC) patients is correlated by Pearson correlation. A positive significant correlation was observed between HOXA9 and ALDH1A1 $(r=0.12, P=0.048)$. (b) The expression of retinoid receptor RXRB and ALDH1A1 in CRC patients is correlated by Pearson correlation. A negative significant correlation was observed between $R X R B$ and $A L D H 1 A 1(r=-0.13$, $P=0.026$ ). (c) The expression of HOXA4 and ALCAM (CD166, SC marker) in CRC patients correlated by Pearson correlation. A negative significant correlation was observed between HOXA4 and ALCAM $(r=-0.14, P=0.024)$. (d) The expression of HOXA9 and ALCAM in CRC patients correlated by Pearson correlation. A positive significant correlation was observed between HOXA9 and ALCAM ( $r=0.18, P=0.0027)$. (e) The expression of HOXD10 and ALCAM in CRC patients correlated by Pearson correlation. A negative significant correlation was observed between HOXD10 and ALCAM $(r=-0.18, P=0.003)$. (f) The expression of HOXB8 and $A L C A M$ in CRC patients correlated by Pearson correlation. A positive significant correlation was observed between HOXB8 and ALCAM $(r=-0.17, P=0.006)$.

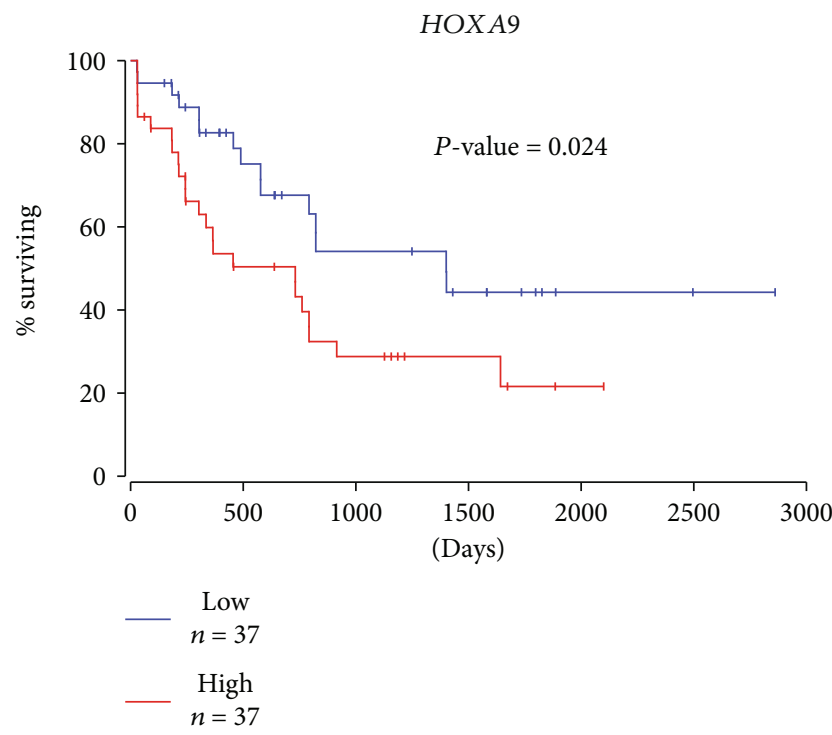

Figure 9: Overall survival analysis for HOXA9 in acute myeloid leukemia. Kaplan-Meier survival analysis of HOXA9 in acute myeloid leukemia (AML) using TCGA dataset. Survival analysis was performed for AML patients (total $n=74$ ) with a cutoff value of 25th percentile. Credits: http://www.oncolnc.org.

tissue sources. The results show that the stromal populations have distinct HOX signatures with different growth and differentiation abilities although they are all immuno- phenotypically similar. These stromal cell populations express different HOX genes and their level of expression varies. Overall, these results indicate that HOX gene profiles can be used to provide positional, embryological, and hierarchical identity of human stromal stem cells [84].

\section{Mechanisms Involved in HOX Gene Dysregulation in Cancer}

3.1. Aberrant Self-Renewal and Proliferation. We have shown that HOXA4 and HOXA9 are upregulated in CRC SCs [49, 50] and that siRNA knockdown of HOXA4 and HOXA9 reduces proliferation and sphere-formation ability of CRC SCs. HOXA4 and HOXA9 knockdown also changed the expression of SC markers, such as ALDH1, ALCAM, (CD166) and LGR5. Treatment of CRC cells with the differentiating agent all-trans-retinoic acid (ATRA) decreased HOXA4, HOXA9, and HOXD10 expression in parallel with decreases in SC levels. Overall, our study demonstrated a role for HOX genes in self-renewal and proliferation of CRC SCs. Thus, strategies designed to modulate HOX expression may provide a means to target malignant SCs and to develop more effective therapies for CRC [50].

Notably, the self-renewal ability of HOXB4 is dependent upon a proline-rich sequence near the $\mathrm{N}$ terminus, which is also unique and highly conserved among the other HOX proteins. Deletion of this domain significantly enhanced the oncogenicity of Hoxb4, promoting features of acute leukemia 
in mice. Insertion of this domain into Hoxa9 impaired oncogenic potential for leukemia. Overall, this study showed that such proline-rich stretches in HOX genes attenuate the potential of SCs to acquire oncogenic properties [85].

\section{HOX Genes and Related Therapeutics}

4.1. HOTAIR Long Noncoding RNA ( $\operatorname{lnc} R N A)$. HOTAIR is a 2.2 kilobase trans-acting lncRNA residing in the HOXC loci that function to repress transcription of 40 kilobases of the HOXD locus. HOTAIR has been shown to interact with polycomb repressive complex 2 (PRC2). Its interaction with PRC2 is required for PRC2 occupancy and histone $\mathrm{H} 2$ lysine-27 trimethylation of the HOXD locus [86]. HOTAIR has been proposed as a biomarker in cervical cancer [87], nasopharyngeal carcinoma [88], and gallbladder cancer [89]. Indeed, meta-analysis involving 748 patients from 8 studies showed HOTAIR is a molecular marker for lymph node metastasis. The results indicated a significant difference in the incidence of lymph node metastasis between high and low HOTAIR expression groups [90]. HOTAIR lncRNA plays a crucial role in epithelial-mesenchymal transitions and is required for the maintenance of colon and breast cancer stem cell stemness [91]. Overall, HOTAIR lncRNA has potential as a therapeutic target in several cancer types. A recent study showed that expression of HOTAIR increased in CRC cells and cell lines and HOTAIR knockdown promoted apoptosis and inhibited proliferation, migration, and invasion in vitro and in vivo. Furthermore, HOTAIR modulated CRC progression by competitively binding miR-197 [92].

4.2. $P B X / H O X$ Dimer. One of the mechanisms that regulates HOX transcriptional expression is through binding with PBX proteins. Both HOX and PBX proteins are known to play critical roles in carcinogenesis, which makes it an attractive therapeutic target for cancers. One study showed that $P B X 3$ is a potential pathologic cofactor of HOXA9 involved in cytogenetically abnormal acute myeloid leukemia (CA-AML), particularly MLL-rearranged AML. The depletion of $P B X 3$ expression by shRNA significantly inhibited MLL-fusionmediated cell transformation, whereas coexpression of $P B X 3$ with HOXA9 promoted cell transformation in vitro and leukemogenesis in vivo. A small peptide, known as HXR9, that disrupts the interaction between HOX and PBX proteins was found to be effective in killing leukemic cells that were overexpressing $H O X / P B X 3$ genes, which suggests a potential therapeutic strategy for CA-AML patients [93]. HXR9 has anticancer effects in other tumor types, such as breast [94], mesothelioma [95], ovarian [96], meningioma [97], prostate [98], and non-small cell lung [99]. Additionally, the disruption of $\mathrm{HOXB7/PBX} 2$ proteins by HXR9 is a potential therapeutic target in malignant melanoma [100]. A recent study also showed that the expression of HOXA5, HOXB2, HOXB4, HOXB9, and HOXC9 (but not HOXA9) in primary AML cases is significantly correlated with survival. HXR9 treatment is cytotoxic to AML-derived cell lines and primary AML cells from patients. And it was shown that cell death is independent of apoptosis. Rather, it involves necroptosis (a regulated form of necrosis) [101]. This study suggests that HXR9 treatment for cancers should be seriously explored in future studies. In addition to the upregulation of HOXA4, HOXA9, and HOXD10 in CRC $[49,50,58]$, the PBX genes are also overexpressed in $\mathrm{CRC}$, which correlates with invasive potential in vitro and lymph node invasion, distant metastasis, advanced TNM stage, and poor overall survival of patients [102]. These reports suggest that HXR9 treatment in CRCs might be therapeutically useful to target HOX/PBX proteins in CRCs.

\section{Conclusion}

The above findings suggest that (i) HOX genes play diverse roles in normal SC functions and properties, from selfrenewal to multilineage differentiation, and (ii) the dysregulation of HOX genes contributes to cancer development through aberrant self-renewal and differentiation of SCs. Thus, understanding the molecular mechanisms for how HOX genes control SC self-renewal and differentiation will ultimately help us understand how SC populations are maintained in normal, disease-free states and how the dysregulation of HOX genes leads to abnormal SC self-renewal and differentiation that drive cancer development. Ultimately, understanding the mechanisms by which HOX genes are regulated in SC might help to find ways to manipulate SC fate resulting in the development of novel, more effective SCtargeted treatments for cancer.

\section{Disclosure}

This work was done at the Center for Translational Cancer Research, Helen F. Graham Cancer Center and Research Institute, Newark, Delaware, and University of Delaware, Newark, Delaware.

\section{Conflicts of Interest}

The authors do not present any conflicts of interest.

\section{Acknowledgments}

The authors thank Dr. Nicholas Petrelli for his ongoing support.

\section{References}

[1] S. C. Quinonez and J. W. Innis, "Human HOX gene disorders," Molecular Genetics and Metabolism, vol. 111, no. 1, pp. 4-15, 2014.

[2] J. F. Loring, J. G. Porter, J. Seilhammer, M. R. Kaser, and R. Wesselschmidt, "A gene expression profile of embryonic stem cells and embryonic stem cell-derived neurons," Restorative Neurology and Neuroscience, vol. 18, no. 2-3, pp. 81-88, 2001.

[3] J. Deschamps and J. van Nes, "Developmental regulation of the Hox genes during axial morphogenesis in the mouse," Development, vol. 132, no. 13, pp. 2931-2942, 2005. 
[4] M. Maconochie, S. Nonchev, A. Morrison, and R. Krumlauf, "Paralogous Hox genes:function and regulation," Annual Review of Genetics, vol. 30, no. 1, pp. 529-556, 1996.

[5] V. Dupé, M. Davenne, J. Brocard et al., "In vivo functional analysis of the Hoxa-1 $3^{\prime}$ retinoic acid response element (3'RARE)," Development, vol. 124, no. 2, pp. 399-410, 1997.

[6] A. Gould, N. Itasaki, and R. Krumlauf, "Initiation of rhombomeric Hoxb4 expression requires induction by somites and a retinoid pathway," Neuron, vol. 21, no. 1, pp. 39-51, 1998.

[7] D. Huang, S. W. Chen, and L. J. Gudas, "Analysis of two distinct retinoic acid response elements in the homeobox gene Hoxb1 in transgenic mice," Developmental Dynamics, vol. 223, no. 3, pp. 353-370, 2002.

[8] A. W. Langston and L. J. Gudas, "Identification of a retinoic acid responsive enhancer $3^{\prime}$ of the murine homeobox gene Hox-1.6," Mechanisms of Development, vol. 38, no. 3, pp. 217-227, 1992.

[9] H. Marshall, M. Studer, H. Pöpperl et al., "A conserved retinoic acid response element required for early expression of the homeobox Gene Hoxb-1," Nature, vol. 370, no. 6490, pp. 567-571, 1994.

[10] C. Nolte, M. Rastegar, A. Amores et al., "Stereospecificity and PAX6 function direct Hoxd4 neural enhancer activity along the antero-posterior axis," Developmental Biology, vol. 299, no. 2, pp. 582-593, 2006.

[11] A. I. Packer, D. A. Crotty, V. A. Elwell, and D. J. Wolgemuth, "Expression of the murine Hoxa4 gene requires both autoregulation and a conserved retinoic acid response element," Development, vol. 125, no. 11, pp. 1991-1998, 1998.

[12] M. Rastegar, L. Kobrossy, E. N. Kovacs, I. Rambaldi, and M. Featherstone, "Sequential histone modifications at Hoxd4 regulatory regions distinguish anterior from posterior embryonic compartments," Molecular and Cellular Biology, vol. 24, no. 18 , pp. 8090-8103, 2004.

[13] M. Studer, H. Popperl, H. Marshall, A. Kuroiwa, and R. Krumlauf, "Role of a conserved retinoic acid response element in rhombomere restriction of Hoxb-1," Science, vol. 265, no. 5179, pp. 1728-1732, 1994.

[14] F. Zhang, E. Nagy Kovács, and M. S. Featherstone, "Murine hoxd4 expression in the CNS requires multiple elements including a retinoic acid response element," Mechanisms of Development, vol. 96, no. 1, pp. 79-89, 2000.

[15] M. Shahhoseini, Z. Taghizadeh, M. Hatami, and H. Baharvand, "Retinoic acid dependent histone 3 demethylation of the clustered HOX genes during neural differentiation of human embryonic stem cells," Biochemistry and Cell Biology, vol. 91, no. 2, pp. 116-122, 2013.

[16] V. Kashyap, L. J. Gudas, F. Brenet, P. Funk, A. Viale, and J. M. Scandura, "Epigenomic reorganization of the clustered Hox genes in embryonic stem cells induced by retinoic acid," Journal of Biological Chemistry, vol. 286, no. 5, pp. 3250-3260, 2011.

[17] E. Ezhkova, H. A. Pasolli, J. S. Parker et al., "Ezh2 orchestrates gene expression for the stepwise differentiation of tissuespecific Stem Cells," Cell, vol. 136, no. 6, pp. 1122-1135, 2009.

[18] X. Wu, Y. Gong, J. Yue, B. Qiang, J. Yuan, and X. Peng, "Cooperation between EZH2, NSPc1-mediated histone H2A ubiquitination and Dnmt1 in HOX gene silencing," Nucleic Acids Research, vol. 36, no. 11, pp. 3590-3599, 2008.
[19] M. Gouti and A. Gavalas, "Hoxb1 controls cell fate specification and proliferative capacity of neural stem and progenitor cells," Stem Cells, vol. 26, no. 8, pp. 1985-1997, 2008.

[20] R. Fan, S. Bonde, P. Gao et al., "Dynamic HoxB4regulatory network during embryonic stem cell differentiation to hematopoietic cells," Blood, vol. 119, no. 19, pp. e139-e147, 2012.

[21] R. A. Alharbi, R. Pettengell, H. S. Pandha, and R. Morgan, "The role of HOX genes in normal hematopoiesis and acute leukemia," Leukemia, vol. 27, no. 5, pp. 1000-1008, 2013.

[22] A. Giampaolo, P. Sterpetti, D. Bulgarini et al., "Key functional role and lineage-specific expression of selected HOXB genes in purified hematopoietic progenitor differentiation," Blood, vol. 84, no. 11, pp. 3637-3647, 1994.

[23] H. Kawagoe, R. K. Humphries, A. Blair, H. J. Sutherland, and D. E. Hogge, "Expression of HOX genes, HOX cofactors, and MLL in phenotypically and functionally defined subpopulations of leukemic and normal human hematopoietic cells," Leukemia, vol. 13, no. 5, pp. 687-698, 1999.

[24] N. Pineault, C. D. Helgason, H. J. Lawrence, and R. K. Humphries, "Differential expression of Hox, Meis1, and $P b x 1$ genes in primitive cells throughout murine hematopoietic ontogeny," Experimental Hematology, vol. 30, no. 1, pp. 49-57, 2002.

[25] G. M. Crooks, J. Fuller, D. Petersen et al., "Constitutive HOXA5 expression inhibits erythropoiesis and increases myelopoiesis from human hematopoietic progenitors," Blood, vol. 94, no. 2, pp. 519-528, 1999.

[26] J. F. Fuller, J. McAdara, Y. Yaron, M. Sakaguchi, J. K. Fraser, and J. C. Gasson, "Characterization of HOX gene expression during myelopoiesis: role of HOX A5 in lineage commitment and maturation," Blood, vol. 93, no. 10, pp. 33913400, 1999.

[27] C. W. So, H. Karsunky, P. Wong, I. L. Weissman, and M. L. Cleary, "Leukemic transformation of hematopoietic progenitors by MLL-GAS7 in the absence of Hoxa7 or Hoxa9," Blood, vol. 103, no. 8, pp. 3192-3199, 2004.

[28] G. Sauvageau, P. M. Lansdorp, C. J. Eaves et al., "Differential expression of homeobox genes in functionally distinct CD34 + subpopulations of human bone marrow cells," Proceedings of the National Academy of Sciences of the United States of America, vol. 91, no. 25, pp. 12223-12227, 1994.

[29] H. J. Lawrence, C. D. Helgason, G. Sauvageau et al., "Mice bearing a targeted interruption of the homeobox gene HOXA9 have defects in myeloid, erythroid, and lymphoid hematopoiesis," Blood, vol. 89, no. 6, pp. 1922-1930, 1997.

[30] H. J. Lawrence, J. Christensen, S. Fong et al., "Loss of expression of the Hoxa-9 homeobox gene impairs the proliferation and repopulating ability of hematopoietic stem cells," Blood, vol. 106, no. 12, pp. 3988-3994, 2005.

[31] C. Buske, M. Feuring-Buske, J. Antonchuk et al., "Overexpression of HOXA10 perturbs human lymphomyelopoiesis in vitro and in vivo," Blood, vol. 97, no. 8, pp. 2286-2292, 2001.

[32] G. Sauvageau, U. Thorsteinsdottir, M. R. Hough et al., "Overexpression of HOXB3 in hematopoietic cells causes defective lymphoid development and progressive myeloproliferation," Immunity, vol. 6, no. 1, pp. 13-22, 1997.

[33] K. H. Ko, Q. L. Kwan Lam, M. Zhang et al., "Hoxb3 deficiency impairs B lymphopoiesis in mouse bone marrow," Experimental Hematology, vol. 35, no. 3, pp. 465-475, 2007. 
[34] S. Amsellem, F. Pflumio, D. Bardinet et al., "Ex vivo expansion of human hematopoietic stem cells by direct delivery of the HOXB4 homeoprotein," Nature Medicine, vol. 9, no. 11, pp. 1423-1427, 2003.

[35] J. Antonchuk, G. Sauvageau, and R. K. Humphries, "HOXB4 overexpression mediates very rapid stem cell regeneration and competitive hematopoietic repopulation," Experimental Hematology, vol. 29, no. 9, pp. 1125-1134, 2001.

[36] J. Antonchuk, G. Sauvageau, and R. K. Humphries, "HOXB4induced expansion of adult hematopoietic stem cells ex vivo," Cell, vol. 109, no. 1, pp. 39-45, 2002.

[37] J. Bijl, A. Thompson, R. Ramirez-Solis et al., "Analysis of HSC activity and compensatory Hox gene expression profile in Hoxb cluster mutant fetal liver cells," Blood, vol. 108, no. 1, pp. 116-122, 2006.

[38] A. C. Brun, J. M. Björnsson, M. Magnusson et al., "Hoxb4deficient mice undergo normal hematopoietic development but exhibit a mild proliferation defect in hematopoietic stem cells," Blood, vol. 103, no. 11, pp. 4126-4133, 2004.

[39] G. Sauvageau, U. Thorsteinsdottir, C. J. Eaves et al., "Overexpression of HOXB4 in hematopoietic cells causes the selective expansion of more primitive populations in vitro and in vivo," Genes \& Development, vol. 9, no. 14, pp. 17531765, 1995.

[40] J. M. Bjornsson, N. Larsson, A. C. M. Brun et al., "Reduced proliferative capacity of hematopoietic stem cells deficient in Hoxb3 and Hoxb4," Molecular and Cellular Biology, vol. 23, no. 11, pp. 3872-3883, 2003.

[41] N. A. Fischbach, S. Rozenfeld, W. Shen et al., "HOXB6 overexpression in murine bone marrow immortalizes a myelomonocytic precursor in vitro and causes hematopoietic stem cell expansion and acute myeloid leukemia in vivo," Blood, vol. 105, no. 4, pp. 1456-1466, 2005.

[42] C. Kappen, "Disruption of the homeobox gene Hoxb-6 in mice results in increased numbers of early erythrocyte progenitors," American Journal of Hematology, vol. 65, no. 2, pp. 111-118, 2000.

[43] K. Takeshita, J. A. Bollekens, N. Hijiya, M. Ratajczak, F. H. Ruddle, and A. M. Gewirtz, "A homeobox gene of the Antennapedia class is required for human adult erythropoiesis," Proceedings of the National Academy of Sciences of the United States of America, vol. 90, no. 8, pp. 35353538, 1993.

[44] A. Daga, M. Podesta, M. C. Capra, G. Piaggio, F. Frassoni, and G. Corte, "The retroviral transduction of HOXC4 into human $\mathrm{CD}_{3}{ }^{+}$cells induces an in vitro expansion of clonogenic and early progenitors," Experimental Hematology, vol. 28, no. 5, pp. 569-574, 2000.

[45] T. Shimamoto, Y. Tang, Y. Naot et al., "Hematopoietic progenitor cell abnormalities in Hoxc-8 null mutant mice," Journal of Experimental Zoology, vol. 283, no. 2, pp. 186-193, 1999.

[46] B. M. Boman, J. Z. Fields, K. L. Cavanaugh, A. Guetter, and O. A. Runquist, "How dysregulated colonic crypt dynamics cause stem cell overpopulation and initiate colon cancer," Cancer Research, vol. 68, no. 9, pp. 3304-3313, 2008.

[47] B. M. Boman and E. Huang, "Human colon cancer stem cells: a new paradigm in gastrointestinal oncology," Journal of Clinical Oncology, vol. 26, no. 17, pp. 2828-2838, 2008.

[48] B. M. Boman, R. Walters, J. Z. Fields et al., "Colonic crypt changes during adenoma development in familial adenomatous polyposis: immunohistochemical evidence for expansion of the crypt base cell population," The American Journal of Pathology, vol. 165, no. 5, pp. 1489-1498, 2004.

[49] S. Bhatlekar, S. Addya, M. Salunek et al., "Identification of a developmental gene expression signature, including HOX genes, for the normal human colonic crypt stem cell niche: overexpression of the signature parallels stem cell overpopulation during colon tumorigenesis," Stem Cells and Development, vol. 23, no. 2, pp. 167-179, 2014.

[50] S. Bhatlekar, V. Viswanathan, J. Z. Fields, and B. M. Boman, "Overexpression of HOXA4 and HOXA9 genes promotes self-renewal and contributes to colon cancer stem cell overpopulation," Journal of Cellular Physiology, vol. 233, no. 2, pp. 727-735, 2018.

[51] S. Liedtke, A. Buchheiser, J. Bosch et al., "The HOX Code as a "biological fingerprint" to distinguish functionally distinct stem cell populations derived from cord blood," Stem Cell Research, vol. 5, no. 1, pp. 40-50, 2010.

[52] C. J. Woo, P. V. Kharchenko, L. Daheron, P. J. Park, and R. E. Kingston, "Variable requirements for DNA-binding proteins at polycomb-dependent repressive regions in human HOX clusters," Molecular and Cellular Biology, vol. 33, no. 16, pp. 3274-3285, 2013.

[53] D. G. Phinney, A. J. Gray, K. Hill, and A. Pandey, "Murine mesenchymal and embryonic stem cells express a similar Hox gene profile," Biochemical and Biophysical Research Communications, vol. 338, no. 4, pp. 1759-1765, 2005.

[54] L. Ye, Z. Fan, B. Yu et al., "Histone demethylases KDM4B and KDM6B promotes osteogenic differentiation of human MSCs," Cell Stem Cell, vol. 11, no. 1, pp. 50-61, 2012.

[55] D. Klein, M. Benchellal, V. Kleff, H. G. Jakob, and S. Ergün, "Hox genes are involved in vascular wall-resident multipotent stem cell differentiation into smooth muscle cells," Scientific Reports, vol. 3, no. 1, article 2178, 2013.

[56] S. P. Atkinson, C. M. Koch, G. K. Clelland et al., "Epigenetic marking prepares the human HOXA cluster for activation during differentiation of pluripotent cells," Stem Cells, vol. 26, no. 5, pp. 1174-1185, 2008.

[57] K. Kitajima, M. Nakajima, M. Kanokoda et al., "GSK3 $\beta$ inhibition activates the CDX/HOX pathway and promotes hemogenic endothelial progenitor differentiation from human pluripotent stem cells," Experimental Hematology, vol. 44, no. 1, pp. 68-74.e10, 2016.

[58] S. Bhatlekar, J. Z. Fields, and B. M. Boman, "HOX genes and their role in the development of human cancers," Journal of Molecular Medicine, vol. 92, no. 8, pp. 811-823, 2014.

[59] G. De Vita, P. Barba, N. Odartchenko et al., "Expression of homeobox-containing genes in primary and metastatic colorectal cancer," European Journal of Cancer, vol. 29A, no. 6, pp. 887-893, 1993.

[60] The Cancer Genome Atlas Network, "Comprehensive molecular characterization of human colon and rectal cancer," Nature, vol. 487, no. 7407, pp. 330-337, 2012.

[61] M. R. Akbari, L. N. Anderson, D. D. Buchanan et al., "Germline HOXB13 p.Gly84Glu mutation and risk of colorectal cancer," Cancer Epidemiology, vol. 37, no. 4, pp. 424-427, 2013.

[62] S. Alanee, F. Couch, and K. Offit, "Association of a HOXB13 variant with breast cancer," New England Journal of Medicine, vol. 367, no. 5, pp. 480-481, 2012. 
[63] C. M. Ewing, A. M. Ray, E. M. Lange et al., "Germline mutations in HOXB13 and prostate-cancer risk," New England Journal of Medicine, vol. 366, no. 2, pp. 141-149, 2012.

[64] M. A. Mansour and T. Senga, "HOXD8 exerts a tumorsuppressing role in colorectal cancer as an apoptotic inducer," The International Journal of Biochemistry \& Cell Biology, vol. 88, pp. 1-13, 2017.

[65] F. Chen, G. Sun, and J. Peng, "RNAi-mediated HOXD3 knockdown inhibits growth in human RKO cells," Oncology Reports, vol. 36, no. 4, pp. 1793-1798, 2016.

[66] Y. Zha, E. Ding, L. Yang et al., "Functional dissection of HOXD cluster genes in regulation of neuroblastoma cell proliferation and differentiation," PLoS One, vol. 7, no. 8, article e40728, 2012.

[67] B. Z. Vider, A. Zimber, E. Chastre et al., "Deregulated expression of homeobox-containing genes, HOXB6, B8, C8, C9, and Cdx-1, in human colon cancer cell lines," Biochemical and Biophysical Research Communications, vol. 272, no. 2, pp. 513-518, 2000.

[68] G. Freschi, A. Taddei, P. Bechi et al., "Expression of HOX homeobox genes in the adult human colonic mucosa (and colorectal cancer?)," International Journal of Molecular Medicine, vol. 16, no. 4, pp. 581-587, 2005.

[69] D. B. Stairs, J. Kong, and J. P. Lynch, "Cdx genes, inflammation, and the pathogenesis of intestinal metaplasia," Progress in Molecular Biology and Translational Science, vol. 96, pp. 231-270, 2010.

[70] C. van de Ven, M. Bialecka, R. Neijts et al., "Concerted involvement of Cdx/Hox genes and Wnt signaling in morphogenesis of the caudal neural tube and cloacal derivatives from the posterior growth zone," Development, vol. 138, no. 16, pp. 3451-3462, 2011.

[71] T. Young, J. E. Rowland, C. van de Ven et al., " $C d x$ and $H o x$ genes differentially regulate posterior axial growth in mammalian embryos," Developmental Cell, vol. 17, no. 4, pp. 516-526, 2009.

[72] A. A. Bhat, A. Sharma, J. Pope et al., "Caudal homeobox protein Cdx-2 cooperates with Wnt pathway to regulate claudin1 expression in colon cancer cells," PLoS One, vol. 7, no. 6, article e37174, 2012.

[73] R. J. Guo, E. Huang, T. Ezaki et al., "Cdx1 inhibits human colon cancer cell proliferation by reducing $\beta$-catenin/T-cell factor transcriptional activity," Journal of Biological Chemistry, vol. 279, no. 35, pp. 36865-36875, 2004.

[74] J. M. Bae, T. H. Lee, N. Y. Cho, T. Y. Kim, and G. H. Kang, "Loss of CDX2 expression is associated with poor prognosis in colorectal cancer patients," World Journal of Gastroenterology, vol. 21, no. 5, pp. 1457-1467, 2015.

[75] P. Dalerba, D. Sahoo, S. Paik et al., "CDX2 as a prognostic biomarker in stage II and stage III colon cancer," New England Journal of Medicine, vol. 374, no. 3, pp. 211-222, 2016.

[76] G. V. Mallo, H. Rechreche, J. M. Frigerio et al., "Molecular cloning, sequencing and expression of the mRNA encoding human Cdx1 and Cdx2 homeobox. Down-regulation of $\mathrm{Cdx} 1$ and $\mathrm{Cdx} 2$ mRNA expression during colorectal carcinogenesis," International Journal of Cancer, vol. 74, no. 1, pp. 35-44, 1997.

[77] O. Lindblad, R. A. Chougule, S. A. Moharram et al., "The role of HOXB2 and HOXB3 in acute myeloid leukemia," Biochemical and Biophysical Research Communications, vol. 467, no. 4, pp. 742-747, 2015.
[78] A. Rio-Machin, G. Gómez-López, J. Muñoz et al., “The molecular pathogenesis of the NUP98-HOXA9 fusion protein in acute myeloid leukemia," Leukemia, vol. 31, no. 9, pp. 2000-2005, 2017.

[79] E. Kroon, J. Krosl, U. Thorsteinsdottir, S. Baban, A. M. Buchberg, and G. Sauvageau, "Hoxa9 transforms primary bone marrow cells through specific collaboration with Meisla but not Pbx1b," The EMBO Journal, vol. 17, no. 13, pp. 37143725, 1998.

[80] A. Takeda, C. Goolsby, and N. R. Yaseen, "NUP98-HOXA9 induces long-term proliferation and blocks differentiation of primary human $\mathrm{CD}_{3} 4^{+}$hematopoietic cells," Cancer Research, vol. 66, no. 13, pp. 6628-6637, 2006.

[81] Y. Shima, M. Yumoto, T. Katsumoto, and I. Kitabayashi, "MLL is essential for NUP98-HOXA9-induced leukemia," Leukemia, vol. 31, no. 10, pp. 2200-2210, 2017.

[82] C. S. Velu, A. Chaubey, J. D. Phelan et al., "Therapeutic antagonists of microRNAs deplete leukemia-initiating cell activity," Journal of Clinical Investigation, vol. 124, no. 1, pp. 222-236, 2014.

[83] H. Fu, L. Fu, C. Xie et al., "miR-375 inhibits cancer stem cell phenotype and tamoxifen resistance by degrading HOXB3 in human ER-positive breast cancer," Oncology Reports, vol. 37, no. 2, pp. 1093-1099, 2017.

[84] J. Picchi, L. Trombi, L. Spugnesi et al., "HOX and TALE signatures specify human stromal stem cell populations from different sources," Journal of Cellular Physiology, vol. 228, no. 4, pp. 879-889, 2013.

[85] M. Cusan, N. M. Vegi, M. A. Mulaw et al., "Controlled stem cell amplification by HOXB4 depends on its unique proline-rich region near the $\mathrm{N}$ terminus," Blood, vol. 129, no. 3, pp. 319-323, 2017.

[86] J. L. Rinn, M. Kertesz, J. K. Wang et al., "Functional demarcation of active and silent chromatin domains in human HOX loci by noncoding RNAs," Cell, vol. 129, no. 7, pp. 13111323, 2007.

[87] L. Huang, L. M. Liao, A. W. Liu et al., “Overexpression of long noncoding RNA HOTAIR predicts a poor prognosis in patients with cervical cancer," Archives of Gynecology and Obstetrics, vol. 290, no. 4, pp. 717-723, 2014.

[88] Y. Nie, X. Liu, S. Qu, E. Song, H. Zou, and C. Gong, "Long non-coding RNA HOTAIR is an independent prognostic marker for nasopharyngeal carcinoma progression and survival," Cancer Science, vol. 104, no. 4, pp. 458-464, 2013.

[89] M. Z. Ma, C. X. Li, Y. Zhang et al., "Long non-coding RNA HOTAIR, a c-Myc activated driver of malignancy, negatively regulates miRNA-130a in gallbladder cancer," Molecular Cancer, vol. 13, no. 1, p. 156, 2014.

[90] B. Cai, Z. Wu, K. Liao, and S. Zhang, "Long noncoding RNA HOTAIR can serve as a common molecular marker for lymph node metastasis: a meta-analysis," Tumour Biology, vol. 35, no. 9, pp. 8445-8450, 2014.

[91] C. Pádua Alves, A. S. Fonseca, B. R. Muys et al., "Brief report: the lincRNA Hotair is required for epithelial-tomesenchymal transition and stemness maintenance of cancer cell lines," Stem Cells, vol. 31, no. 12, pp. 2827-2832, 2013.

[92] X. Lu, Z. Liu, X. Ning, L. Huang, and B. Jiang, "The long noncoding RNA HOTAIR promotes colorectal cancer progression by sponging miR-197," ncology Research Featuring Preclinical and Clinical Cancer Therapeutics, vol. 26, no. 3, pp. 473-481, 2018. 
[93] Z. Li, Z. Zhang, Y. Li et al., "PBX3 is an important cofactor of HOXA9 in leukemogenesis," Blood, vol. 121, no. 8, pp. 14221431, 2013.

[94] R. Morgan, A. Boxall, K. J. Harrington et al., Breast Cancer Research and Treatment, vol. 136, no. 2, pp. 389-398, 2012.

[95] R. Morgan, G. Simpson, S. Gray et al., "HOX transcription factors are potential targets and markers in malignant mesothelioma," BMC Cancer, vol. 16, no. 1, p. 85, 2016.

[96] Z. Kelly, C. Moller-Levet, S. McGrath et al., "The prognostic significance of specific $H O X$ gene expression patterns in ovarian cancer," International Journal of Cancer, vol. 139, no. 7, pp. 1608-1617, 2016.

[97] H. Ando, A. Natsume, T. Senga et al., "Peptide-based inhibition of the HOXA9/PBX interaction retards the growth of human meningioma," Cancer Chemotherapy and Pharmacology, vol. 73, no. 1, pp. 53-60, 2014.

[98] R. Morgan, A. Boxall, K. J. Harrington, G. R. Simpson, A. Michael, and H. S. Pandha, "Targeting HOX transcription factors in prostate cancer," BMC Urology, vol. 14, no. 1, p. 17, 2014.

[99] L. Plowright, K. J. Harrington, H. S. Pandha, and R. Morgan, "HOX transcription factors are potential therapeutic targets in non-small-cell lung cancer (targeting HOX genes in lung cancer)," British Journal of Cancer, vol. 100, no. 3, pp. 470475, 2009.

[100] M. C. Errico, F. Felicetti, L. Bottero et al., "The abrogation of the HOXB7/PBX2 complex induces apoptosis in melanoma through the miR-221\&222-c-FOS pathway," International Journal of Cancer, vol. 133, no. 4, pp. 879-892, 2013.

[101] R. A. Alharbi, H. S. Pandha, G. R. Simpson et al., "Inhibition of HOX/PBX dimer formation leads to necroptosis in acute myeloid leukemia cells," Oncotarget, vol. 8, no. 52, pp. 89566-89579, 2017.

[102] H. B. Han, J. Gu, D. B. Ji et al., "PBX3 promotes migration and invasion of colorectal cancer cells via activation of MAPK/ERK signaling pathway," World Journal of Gastroenterology, vol. 20, no. 48, pp. 18260-18270, 2014. 


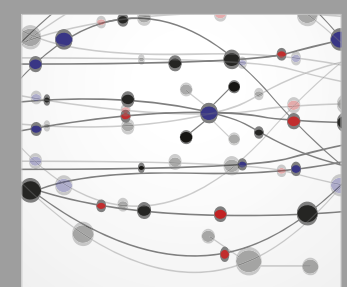

The Scientific World Journal
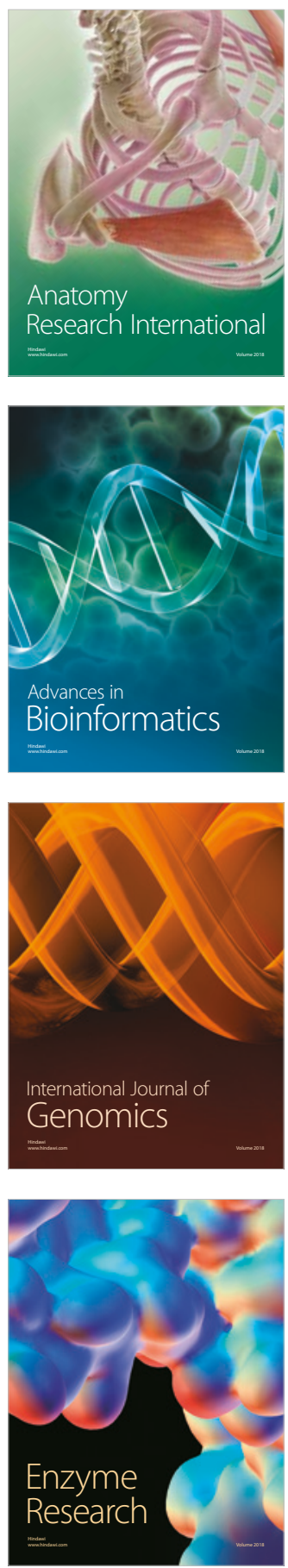
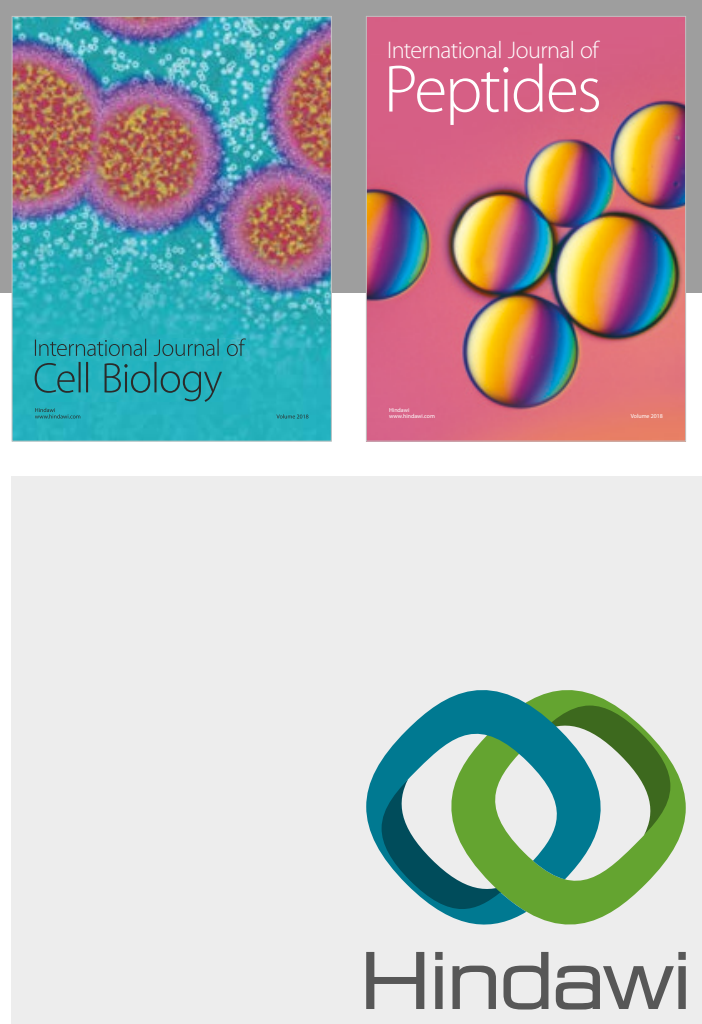

Submit your manuscripts at

www.hindawi.com
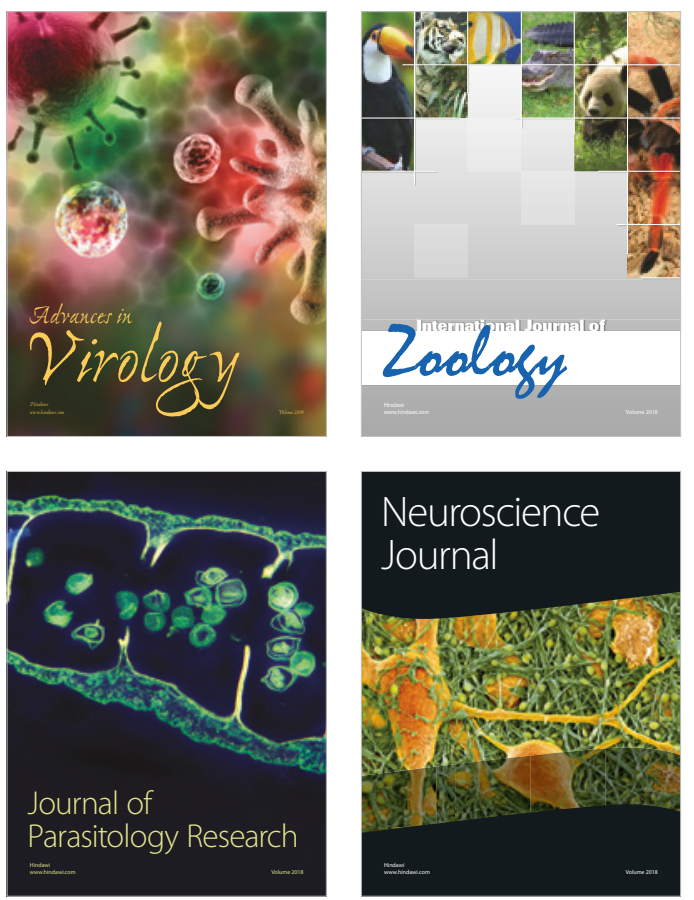
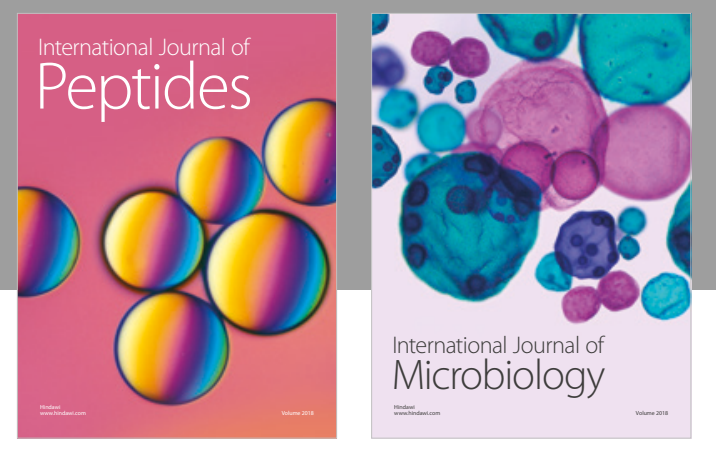

nternational Journal of Microbiology
Journal of
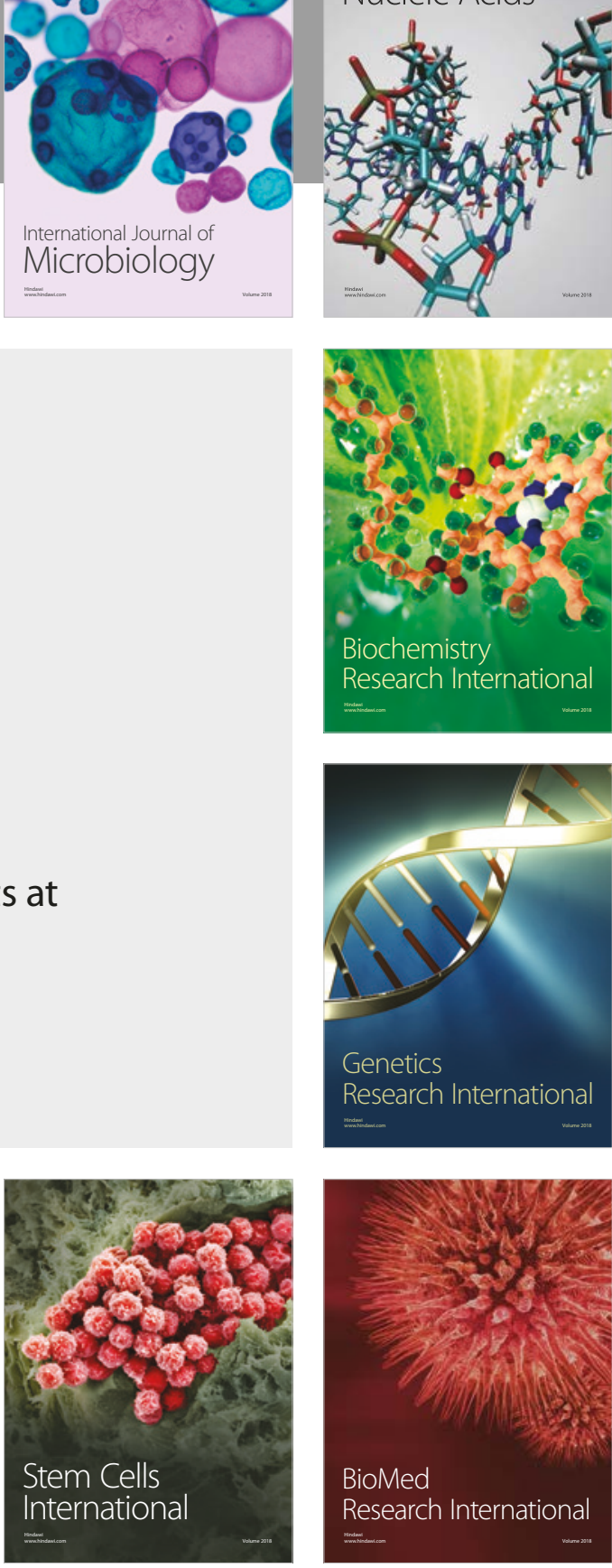
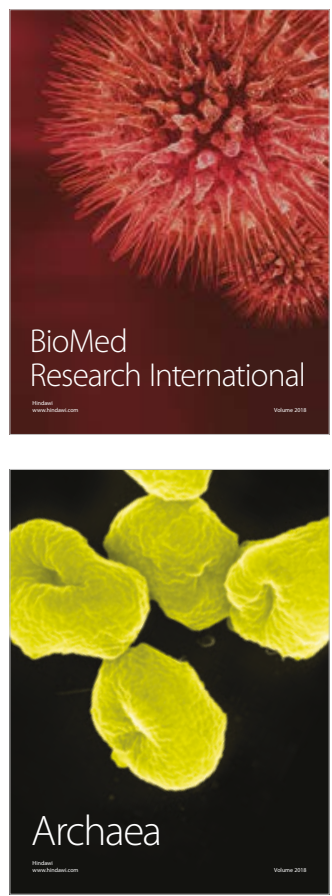